Defraeye T., Advanced computational modelling for drying processes - a review, Applied Energy 131, 323-344. http://dx.doi.org/10.1016/j.apenergy.2014.06.027

\title{
Advanced computational modelling for drying processes - a review
}

Thijs Defraeye ${ }^{a, b, c *}$

${ }^{a}$ MeBioS, Department of Biosystems, University of Leuven, Willem de Croylaan 42, 3001 Heverlee, Belgium

${ }^{b}$ Laboratory for Building Science and Technology, Swiss Federal Laboratories for Materials Testing and Research (Empa), Überlandstrasse 129, 8600 Dübendorf, Switzerland

${ }^{c}$ Chair of Building Physics, Swiss Federal Institute of Technology Zurich (ETHZ), Wolfgang-Pauli-Strasse 15, 8093

Zürich, Switzerland

\section{Highlights:}

- Understanding product dehydration is a key aspect in drying technology

- Advanced modelling thereof plays an increasingly important role for developing next-generation drying technology

- Dehydration modelling should be more energy-oriented

- An integrated "nexus" modelling approach is needed to produce more energy-smart products

- Multi-objective process optimisation requires development of more complete multiphysics models

\footnotetext{
${ }^{*}$ Corresponding author. Tel.: +32 (0)16321618; fax: +32 (0)16322966.
}

E-mail address: thijs.defraeye@biw.kuleuven.be 


\begin{abstract}
Drying is one of the most complex and energy-consuming chemical unit operations. R\&D efforts in drying technology have skyrocketed in the past decades, as new drivers emerged in this industry next to procuring prime product quality and high throughput, namely reduction of energy consumption and carbon footprint as well as improving food safety and security. Solutions are sought in optimising existing technologies or developing new ones which increase energy and resource efficiency, use renewable energy, recuperate waste heat and reduce product loss, thus also the embodied energy therein. Novel tools are required to push such technological innovations and their subsequent implementation. Particularly computer-aided drying process engineering has a large potential to develop next-generation drying technology, including more energy-smart and environmentallyfriendly products and dryers systems. This review paper deals with rapidly emerging advanced computational methods for modelling dehydration of porous materials, such as many foods. Drying is approached as a combined multiphysics, multiscale and multiphase problem. These advanced methods include computational fluid dynamics, several multiphysics modelling methods (e.g. conjugate modelling), multiscale modelling and modelling of material properties and the propagation of material property variability. Apart from the current challenges identified for each of these, future perspectives should be directed towards material property determination, model validation, more complete multiphysics models and more energy-oriented and integrated "nexus" modelling of the dehydration process. Development of more user-friendly, specialised software is paramount to bridge the current gap between modelling in research and industry by making it more attractive. These advanced computational methods show promising perspectives to aid developing next-generation sustainable and green drying technology, tailored to the new requirements for the future society, and are expected to play an increasingly important role in drying technology R\&D.
\end{abstract}

Keywords: food; dehydration; energy-smart; CFD; nexus; multiphysics 


\section{Introduction}

Drying (also dehydration or dewatering) implies removing moisture from natural or industrial materials down to a specific moisture content, while ensuring at the same time prime product quality, high throughput and minimal operational costs. Drying is applied amongst others for processing food, textile, paper, wood, ceramics, minerals, wastewater sludge, pharmaceutical products or biotechnological products [1]. As one of the most energyintensive unit operations in industry, drying can use about $10 \%-25 \%$ of the national energy consumption for industrial processes [1-3].

Though drying is a well-established unit operation in chemical engineering [4], the current dryers, with a typical lifetime of a few decades, were not designed for a world where energy usage has become an important part of the operational and lifecycle cost of a dryer and where the use of environmentally-friendly technology is strongly encouraged. The underlying drivers here are climate change, the limited amount of natural resources to produce energy, but especially the steep rise in global energy consumption (expected to increase with one third by 2035, [5]), due to the rapid industrial and demographic expansion in developing economies. Despite the fast progress in developing more sustainable, energy-smart drying technology in the past decades (Figure 1), such efforts are expected to increase even more in the future. Here, evolutionary and revolutionary technological innovations, driven by the need to reduce energy demand and carbon footprint, particularly aim at improving energy efficiency, increasing the use of renewable energy and recuperating waste heat. At the same time however, innovative drying technologies should also strive to improve product quality but also to develop novel products [6]. Furthermore, material losses should be minimised (turndown ratio) in order to use our resources more efficiently and as a large amount of energy is embodied in dried products, which is lost indirectly in that way.

Due to these new boundary conditions and continuously emerging new feedstock, existing technologies are currently revised and optimised or intelligently combined (e.g. multistage and hybrid dryers; [7-10]), but also entirely new processes and equipment are developed. Several of these advanced innovative drying technologies and the accompanied R\&D challenges have been discussed in literature [6,10-14]. Their successful integration in an industrial process chain is however often uncertain, as significant benefits compared to existing technology are required to find industrial acceptance. This originates from the large timescales involved in this industry, which slows down implementation of new technologies and leads to long payback times [6]. As such, hardware replacement is often done in the context of retrofitting or upgrading existing dryer systems rather than implementing novel systems [13].

Optimizing existing drying technologies or developing novel technological concepts requires a simultaneous leap forward in drying-process analysis methods, both experimental or numerical, in order to create more means to fine-tune drying processes and to deal with the added complexity of these state-of-the-art technologies. Such methods are currently used to assist in: (1) design and performance assessment of dryer equipment and systems, as well as troubleshooting of existing plants [15]; (2) dynamic (online) drying process control [8,16-18]; (3) optimisation of the dehydration process of the (porous) product itself within the drying unit $[19,20]$. For the latter, the drying industry currently still heavily relies on laboratory or pilot plant studies but also on basic process calculations, mathematical models or process simulation software (e.g. [15,21-25]). Such software is developed at different levels of complexity for dealing with the dehydration process, as discussed in detail by [15,26,27], and mostly involves basic programs for dryer design and selection, process simulation and control (heat and mass balances) or cost estimation. The use of advanced computational methods for more in-depth analysis of dehydration processes, of which computational fluid dynamics (CFD) is probably the most well-known, has received much less attention $[1,12,28]$. By explicitly modelling (part) of the complex physical processes occurring during drying (e.g. using CFD or finite-element modelling), these computational methods can aid in enhancing 
product quality (e.g. residual moisture content, case hardening or cracking, nutritional content for food), ensuring inter-product uniformity, optimising drying conditions or reducing drying time, product waste and energy consumption of the drying process [26]. The use and acceptance of such numerical methods by the drying community and industry is however limited, for which several factors are responsible:

- Drying involves multiphase transport processes at multiple scales, where multiple physical processes are involved. This multicubed nature of the drying process (multicubed implies multi ${ }^{3}$ : multiphase, multiscale and multiphysics) is responsible for the complexity and challenges encountered while modelling them, and the reluctance of undertaking such effort. Modelling these transport processes inside porous materials is currently considered one of the major hurdles in drying modelling [15].

- Numerical modelling of dehydration of porous materials requires knowledge on material properties, which are often not known, change during processing, have a complex dependency on temperature and moisture content, and exhibit a large inter- and intra-sample variability $[19,28,29]$. Obtaining materialproperty data is time-consuming and requires specialised equipment, which is also a major hurdle when applying numerical modelling for drying analysis.

- For low-value items, such as many foods, the additional effort of modelling the dehydration process can often not be economically justified.

- User-friendly modelling tools embedded in advanced (commercial) software, customised to the specific applications drying engineers need them for, are not readily available and scarce [15]. The main reasons are that the customer base for such specialized drying software tools is rather limited and that a dryer is very complex, specialized equipment, of which hundreds of types exists. As such, mostly in-house codes are developed by academics or large companies, or commercial software is customized by implementing submodels, which is often not straightforward for most users [28]. Either way, significant expertise is required from the user. In the development of such tools, there is currently a gap between research and industry, due to different requirements set forth by both: where industrial users need fast, user-friendly (commercial) tools for realistic 3D engineering problems, academics rather develop in-house (open source) tools to study more fundamental aspects of drying processes, which are currently out of reach of commercial software, and apply them on simplified (2D) geometries.

Advanced numerical modelling however has some unique advantages compared to drying experiments in laboratory setups, pilot plants or even full-scale facilities:

- Simulations actually imply having non-intrusive, virtual sensors or monitors in nearly each point (i.e. of the computational mesh). As such the distribution of all variables (temperature, moisture content, velocity, etc.) within the product and its surroundings is available at very high spatial and temporal resolution, even at scales or locations which are difficult to access experimentally. Such 3D information leads to a deeper physical insight and understanding of the drying process, which can feed new ideas for (re)designing or optimising drying processes.

- Heat and mass flows during drying can be quantified throughout space and time, which both play a key role in energy optimisation, waste heat recuperation and dehumidification of return air.

- Sensitivity to small changes, such as drying conditions, can be detected as no "experimental uncertainty" or problems with repeatability are present, e.g. due to varying operating conditions or sample material properties.

- The predictive capability inherent to modelling allows a-priori design and optimisation of drying processes or dryers, in a virtual way, without the cost and effort of constructing a scaled or full-scale setup and the time needed to perform experiments. 
- The use of multi-objective process optimization methods can turn the numerical model into a proactive design and analysis tool.

- No limitations are present with respect to the drying conditions (e.g. hostile environments at high temperature) and safety is also not an issue.

- No scale-up issues are present. Reduced-scale experiments on laboratory or pilot plant setups often experience difficulties to relate/upscale their results to full-scale dryer setups, as the processes occurring are highly nonlinear. Numerical simulations on the other hand can be performed at the actual scale $[15,30]$.

- Modelling does not require additional lab space, maintenance and technical personnel to operate the equipment but also avoids the high energy costs inherent to drying.

These particular advantages are responsible for the major push forward of computational methods in drying process engineering in the past decades (see Figure 1). Advanced computational modelling is however not expected to provide an added value for every drying process nor be cost-beneficial here, compared to more simplified methods. Nevertheless, computer-aided drying process engineering (CADPE) [17] is envisaged to be decisive in taking evolutionary steps in conventional drying process optimization or to help conceptualise, design and optimise next-generation drying processes. CADPE should allow to tailor them to the (energy) requirements for the future drying industry, to make them cost-beneficial, which is the single most important criterion for industrial implementation [31,32], and to optimise product quality or even design new materials, such as foods with improved functional properties [33-37]. This will not be an easy task, given the intrinsic interdisciplinary character of drying technology, which encompasses material science, chemical and mechanical engineering, energy technology and even food technology [30]. R\&D efforts in CADPE will thus require an unprecedented integrative and multidisciplinary approach in order to develop such next-generation sustainable and green drying technology.

This review focusses on advanced computational methods which are currently emerging and which show large potential for computer-aided drying process engineering, both at research level as well as in an industrial context. The computational methods discussed here are those intended for modelling dehydration of the material in the drying chamber in particular, so where the product to be dried is the core focus, and not as such for modelling drying process control or design, and performance or cost assessment of entire dryer plants, for which other, less advanced process simulation tools are available $[15,26,27]$. The main reason to target the product dehydration process itself is that its understanding is a key aspect for the evaluation and optimisation of drying processes, as it affects product quality, product losses and associated loss of embodied energy, product throughput, energy usage, energy efficiency and possible recuperation of waste heat. The focus of this review is primarily on convective drying, or hybrid technologies thereof, as they comprise the majority of all drying processes [1]. Both drying of macroscopic porous products as well as microscopic products, such as droplets and particles, are considered. The modelling methods are approached from a multicubed perspective, but particularly concentrate on the larger scales, which are most relevant to industry. The reader will notice that the review is oriented particularly towards food applications, for which there are a few good reasons. In the food industry, which accounts for about 30\% of the world's energy consumption [38], drying comprises an important and energy-intensive unit operation [39], as most foods require drying of at least a part of the product at some stage during processing (roughly $34 \%$ in weight of the world's produce, [11]). These foods can be both natural products (fruits, vegetables, herbs, meat and fish) as well as manufactured foods (e.g. instant foods and nutraceuticals). In addition, foods are amongst the most challenging materials to dry properly, due to their complex, multiscale nature, the large range of multiphysics transport processes that occur during drying and their inherent large biological variability. For these reasons, research efforts on drying of food materials have been extensive (Figure 
$1,[1,6,30,40-42])$. This review starts off with presenting the multicubed nature of the drying process, after which a general background on modelling of drying processes is given. Consequently, several advanced computational methods are discussed, and future perspectives are given for each of them. To end with, more general challenges in the context of advanced modelling methods for drying are presented, including an outlook towards more integrated and interdisciplinary modelling for developing energy-smart, environmentally-friendly drying technology.

\section{Drying: a multicubed problem}

\subsection{Multiphase}

The vast majority of all drying processes involves the removal of water from a porous material leading to dehydration [1]. Multiple phases are present in these materials: (1) the solid phase, being the dry material matrix, but also ice, for example during freeze drying; (2) Liquid water, which can exist in different states: unbound (free) water, physically-bound (adsorbed) water and chemically-bound water (e.g. in gypsum or cement-based materials); (3) Gas, namely water vapour and dry air $\left(\mathrm{O}_{2}, \mathrm{~N}_{2}, \mathrm{CO}_{2}\right)$ but also other gasses, for example ethylene in fruit.

\section{$\underline{2.2}$ Multiscale}

With transport and exchange processes occurring at multiple spatial and temporal scales, drying has a distinct multiscale nature. Typical scales involved are illustrated in Figure 2 for some products relevant for the drying industry. They clearly have a different composition at each scale. Note that these scales overlap to some extent and are quite product specific. They are defined here, rather arbitrary, as follows:

- Dryer scale $\left(\sim 10^{-1}-10^{3} \mathrm{~m}\right)$, i.e. at the level of an entire dryer facility. Individual (porous) products to be dried (in the drying chamber) can be distinguished, but appear homogeneous themselves. The different components making up the product cannot be distinguished. Such components are, for example, cement and aggregates in concrete (see Figure 2).

- Macroscale $\left(\sim 10^{-2}-10^{1} \mathrm{~m}\right)$, i.e. at the level of a single product. Different product components can be distinguished, as well as macro-cracks, though each component appears homogeneous.

- Mesoscale $\left(\sim 10^{-4}-10^{-2} \mathrm{~m}\right)$, i.e. at the level of a single component within a product. Different constituents of a component (e.g. latewood and earlywood, see Figure 2) can be distinguished as well as macro-pores, inclusions, constituent interfaces or droplets on surfaces. Each constituent appears homogeneous.

- Microscale $\left(\sim 10^{-6}-10^{-4} \mathrm{~m}\right)$, i.e. at level below a single constituent. Within a constituent, micro-pores and micro-capillaries, grains, fibres, micro-crystals, pits in wood, or plant/fruit cells can be distinguished.

- Nanoscale $\left(\sim 10^{-6}-10^{-9} \mathrm{~m}\right)$. Examples are nano-capillaries, cell walls and the cellulose microfibrils of which it is composed, cell membranes and aquaporins therein.

\section{$\underline{2.3 \text { Multiphysics }}$}

Drying is also a multiphysics problem, where coupled heat, mass and momentum transport processes occur inside the material and also exchange processes with the environment take place at air-material (or material-material) interfaces. The transport and exchange processes involved are prescribed by the applied drying technique and the specific material of interest. The most relevant physical processes involved in drying are presented in Figure 3 , which are also the ones that should be captured by associated modelling. For more detailed information on both transport and exchange processes, within the perspective of drying modelling, the reader is referred to the following books $[43,44]$ or studies $[19,20,45-47]$, amongst others. 
Materials particularly differ with respect to their water (liquid \& vapour) transport pathways at the microscale, which are intrinsically linked to their microstructure. Typical examples are (see also Figure 3): mono- and multilayer (ad-and de)sorption of (physically bound) water onto pore walls of hygroscopic materials [48]; capillary transport in the pore system of stone or soil [49] which can include liquid film flows [50-52], but also in textiles (called wicking here); apoplastic, symplastic and transcellular pathways for water transport in plant tissue [53]; water transport through bordered pits in wood tracheids, where the elastic pit membrane allows dynamic opening or closing of the pit, which can prevent embolism [54]. These differences at the lower scales induce a fundamentally different drying behaviour at higher scales.

In addition to these physical processes which occur during drying, (bio)chemical processes can take place as well, especially for biological products such as food. Typical examples are degradation processes such as reduced nutrient and enzyme retention, changes in aroma or color, fat oxidation or microbiological activity [55-57]. Though we will not go into detail in this review, these (bio)chemical changes during drying, and modelling these, is of paramount importance, for example when dealing with food safety or nutritional and organoleptical (sensory) quality $[16,35]$, and is at the same time very challenging.

\section{Drying processes modelling at different scales}

Several numerical approaches have been set forth to model heat, mass and momentum transfer during dehydration of a porous material. The chosen approach is prescribed by the spatial scale and the physical processes to be captured. The most common modelling methods are discussed below at the scales they are typically applied to model drying processes. Note however that some methods can inherently deal with a wider range of length scales [58].

At dryer scale and macroscale, but also at mesoscale, so called macroscopic models are commonplace. These models assume the material as a continuum. Each point within the material is considered to be the centre of a socalled representative elementary volume (REV). In such a REV, the individual phases are assumed superimposed to one another, which implies they cannot be distinguished separately. REVs should be sufficiently large, e.g. larger than the pore size, to allow representative averaging of material properties within a REV. In contrast, a REV should also be small enough to avoid variations of quantities within the REV (e.g. temperature) due to macroscopic gradients and associated non-equilibrium conditions at this microscale level (e.g. [59]). Transport inside the material is modelled by (effective) material properties $[19,29,46,60]$, which are obtained experimentally or via numerical simulation at smaller scales ([59], section 4.3 and 4.4). As such, the complex transport pathways and processes at microscale level and below (section 2.3) are included in a lumped way in the material (transport) properties and transport equations, rather than accounting for them explicitly by modelling at the microscale level. A typical example is the use of Darcy's law in combination with a liquid permeability (Figure 3), i.e. a macroscopic material property, to describe liquid transport inside a porous material at continuum level, which inherently includes the complex transport phenomena at microscale level, such as liquid film flows. These material properties are often a complex function of temperature, moisture content but also deformation state.

The governing equations for macroscopic models are obtained by: (1) the phenomenological approach [61-63]; (2) the approach based on mixture theory [64-67]; (3) the mechanistic (first-principle based) approach, which relies on volume-averaging microscopic conservation equations for each phase [68-71], but also a moving evaporation boundary formulation was put forward, which assumes a sharp interface where evaporation takes place in the material $[72,73]$. Continuum (macroscopic) models are typically solved by means of finite element, finite volume or finite difference methods $[74,75]$. 
At lower scales, other modelling methods are more appropriate to model multiphase flow in porous materials, amongst others since the validity of the continuum hypothesis can be compromised [76-78]. For drying at mesoto microscale, the most well-known method is pore network modelling [49,51,79-85]. Here, the microstructure of the porous material is explicitly modelled, namely by representing it as a network of pores interconnected by socalled throats. They are mainly used to study or determine macroscopic material (transport) properties at the scale of the REV (e.g. permeabilities), i.e. those used in continuum models, and to understand drying at a mesoscale (sample) level in a more fundamental way since the impact of the pore microstructure and transport therein on the drying kinetics can be assessed explicitly $[50,51,80]$, amongst others the impact of liquid film flows.

Other lower-scale simulations, discussed below, are rarely performed within the framework of industrial drying processes, but rather to gain fundamental understanding in wetting/drying phenomena of materials in various research fields. When modelling drying-related transport processes at the pore-scale level (i.e. micro- and nanoscale), for example capillary transport in pores or water adsorption at pore walls, following methods are applied, amongst others: Lattice Boltzmann method [86], smooth particle hydrodynamics, dissipative particle dynamics, the material point method but also conventional CFD [87]. A review on these methods can be found in [58]. At the lowest scale (nanoscale), molecular dynamics is commonplace [88,89].

At any scale, drying process modelling also requires accurate modelling of the exchange processes with the environment, such as convective and radiative exchange (Figure 3), and, for particles or droplets, of the particle dynamics and their interactions in the dryer. These will be dealt with in section 4 .

Most modelling research and software development on drying processes have been performed at the dryer and macroscale level $[17,28,59]$. The reason for this is that these scales are directly relevant for industry and for corresponding experimental research on pilot plants, with which both researchers and engineers have a closer affinity. As such, macroscale (or continuum-based) modelling in particular has the best perspectives to be integrated as one of the cornerstones in industrial drying process design and optimization [28,31]. The advanced modelling methods developed within this perspective are the main focus of this review.

Despite remarkable advances in model development at lower scales by various research groups $[58,80]$, these models had less exposure in drying technology so far due to the required high-level expertise, which is not part of a standard engineering curriculum, and the complexity experienced when coupling or transferring the results to higher scales. Nevertheless, lower-scale modelling should deserve more attention in the future as our fundamental understanding of transport phenomena at these scales is still lacking but is paramount to advance beyond the current state-of-the-art in drying technology. A typical example here is how changes to food microstructure, e.g. as induced by pre-treatments [11,90], can be of key importance to improve macroscopic drying behaviour and product quality [91,92].

Finally, it needs to be said that these existing models for dehydration of porous materials predominantly focus on the physics of the drying process. They are however rarely used to target other aspects as well, such as energy efficiency, consumption and recuperation, product losses and energy embodied therein, biochemical and organoleptic aspects of (food) quality (e.g. nutritional content of food, colour), etc. Nevertheless, interesting perspectives towards a more integrated modelling approach are present, as detailed below (section 4.2 .3 and 5.4).

\section{Advanced modelling methods}

Several advanced computational methods for drying of porous materials have clearly emerged in the past decade, of which some examples are given in Figure 4. The ones discussed below were selected based on their envisaged 
potential to become more firmly established within the drying community in the near future, due to their ability to develop next-generation drying processes combined with expected improvements in access and userfriendliness of modelling tools for researchers and engineers. These methods include (1) CFD for modelling airflow, but also particle motion, thus multiphase modelling; (2) multiphysics modelling, implying here modelling heat and mass transport in the product coupled with external airflow (conjugate modelling), with hygromechanical deformation or with other physical processes within the material; (3) multiscale modelling of drying processes; (4) modelling of material properties and the propagation of material property variability into the simulation results.

Previous reviews on advanced computational methods for drying include Perré [93] and Frank and Perré [58], which however focussed on the pore-scale level. Wang and Sun [74] and Datta [28] reviewed such modelling for the food industry in general, including drying processes amongst others. Some advanced computational tools for drying were included in the book of Tsotsas and Mujumdar [43]. These previous works however do not make the present review less timely, given the rapid evolution of modelling techniques in drying technology (Figure 4) and since its focus is particularly on modelling at the dryer-/macroscale and on all types of materials, including but not limited to food. This review particularly targets recent developments and provides a fresh outlook for each of the aforementioned modelling methods.

\subsection{Computational fluid dynamics}

CFD is probably the most well-known and widespread advanced modelling method treated in this review. It has been applied, amongst others, for convective dryers, spray dryers, tray dryers, flash dryers, fluidized and sprouted bed dryers. The use of CFD in drying technology is rapidly expanding (Figure 4) and was recently reviewed by Jamaleddine and Ray [94], with a particular focus on gas-solid (particle/droplet) multiphase flow. Other reviews were devoted to its use for spray drying [95-98] or for food processing operations, drying being one of them [99101].

A new survey was performed by the author on the recent use of CFD in drying technology, by considering relevant journal publications on CFD from 2008 till 2013 (see Appendix 1). This survey identified that food (still) makes up an important part of all materials considered. Commercial software is mainly used, particularly ANSYS Fluent and ANSYS CFX. For turbulence modelling, the Reynolds-Averaged Navier-Stokes approach (RANS) dominates, mostly in combination with two-equation turbulence models ( $k-\varepsilon$ and $k-\omega$ models) and wall functions. This recent survey also revealed that 2D modelling still is used extensively next to 3D modelling (about 50/50). The same holds for steady-state and transient modelling (also about 50/50). Below, the most prominent applications of CFD for drying modelling are discussed and current knowledge gaps and perspectives are given. The reader will find it maybe surprising that the use of CFD for energy optimisation of drying processes is not included. The reason is that it is just not often used (yet) for this purpose [102,103], despite its particular advantage of quantifying heat (enthalpy) and mass flows in dryer systems (e.g. at dryer chamber inlet, outlet and walls but also at product interfaces), which provides a significant added value when compared to experiments.

\subsubsection{Inhomogeneities in flow field}

Its high spatial and temporal resolution makes CFD one of the most appropriate tools to increase our understanding of airflow as well as temperature and humidity fields in dryer systems. Researchers and engineers readily apply CFD to identify inhomogeneities therein [104-108], as these induce variability in drying behaviour and product quality. This knowledge is applied to design and optimise drying equipment (e.g. dryer chamber geometry) and processing strategies. 
Despite the numerous research efforts towards detailed validation of CFD simulations, the (absolute) accuracy of CFD simulations is still often criticised in the drying community, and is argued to be too limited for practical use [94]. Such criticism and scepticism towards CFD, or modelling techniques in general, is however not always justified. Furthermore, for problems related to identifying flow-field inhomogeneities, quantitative accuracy can be considered of less importance as a qualitative comparison of flow fields, for example in different dryer designs, is often already sufficient for practical applications.

The accuracy of such flow-field predictions is largely determined by the turbulence modelling approach used. The RANS approach, which still fully dominates CFD research in drying, has the inherent disadvantage that all scales of turbulence are modelled by means of a turbulence model (e.g. k- $\varepsilon$ or k- $\omega$ models), which can reduce the accuracy of flow predictions. In addition, as no turbulence model is universally valid [109], the turbulence-model choice for each specific case has to be guided by experience and validation studies. The need for more accurate flow-field (thus turbulence) predictions has directed researchers in drying towards more advanced turbulence-modelling approaches, such as the scale-adaptive simulation (SAS) approach [110], the (very) large-eddy simulation $[111,112]$ and hybrid RANS-LES techniques (detached-eddy simulation, [95,98]). Their increased accuracy originates from explicitly resolving a part of the turbulence instead of modelling all of it (LES, DES) or from accounting for turbulence length scales in a more realistic way than RANS (SAS). Such (transient) modelling is however accompanied by an increase in required user expertise, computational cost and postprocessing effort. These hurdles make that these advanced alternatives to RANS are only just surfacing in drying technology [112]. Note however that they are readily available in commercial software and are already commonly applied in other fields of research.

\subsubsection{Convective transfer coefficients}

Convective transfer coefficients (CTCS) are commonly used in drying modelling to predict the convective heat and mass exchange of macroscopic porous materials or microscopic particles/droplets with the environment at the air-material interface via the boundary layer. This is however done in a quite simplified way [46], as CTCs are often taken from existing empirical correlations with the air speed (e.g. for flat plate or sphere), their spatial and/or temporal variation is usually not accounted for and convective mass transfer coefficients (CMTCs) are often directly estimated from convective heat transfer coefficients (CHTCs) by using the heat and mass transfer analogy [113], though the conditions under which the analogy is valid are often not fulfilled.

The use of such simplified CTCs essentially circumvents accounting for the case-specific nature of the transport in the boundary layer. This facilitates an important part of the modelling of complex drying processes, but on the other hand can seriously compromise the accuracy of the air-side convective heat and mass transfer predictions [46,75]. CFD has proven to be a viable alternative for predicting CTCs $[46,74,107,114-119]$, compared to experiments (e.g. [120]). A particular advantage is that the actual complexity found in the specific dryer of interest is incorporated in the CTCs at a high degree of detail, including the local spatial variability over product surfaces.

Some recent advances in CTC predictions with CFD, relevant to drying, are worthwhile mentioning. A cross-scale modelling approach was applied by Defraeye et al. $[119,121]$ to investigate the impact of partial coverage of surfaces by microscopic droplets $\left(10^{-5} \mathrm{~m}\right)$ on the resulting CTCs from the surface. The large range of length scales included in the model (from droplet $10^{-5} \mathrm{~m}$ to surface $10^{-1}$ ) allowed to unveil the complex dependency of the CTCS on the surface coverage of the droplets, air speed and droplet size. Furthermore, the combined spatial and temporal variability of CTCs during drying was recently identified by means of conjugate modelling ([46], Figure 5). Conjugate modelling, detailed in section 4.2.1, allows to determine CTCs a-posteriori. A distinct temporal CTC variability was unveiled to a very high degree of detail (Figure 5), showing interesting peak behaviour, particularly 
between the constant drying rate period (CDRP) and the decreasing drying rate period (DDRP). Such temporal variability was also reported for conjugate modelling in food processing $[122,123]$.

Next to turbulence modelling (see section 4.1.1), the accuracy of convective exchange predictions with CFD at airmaterial interfaces during drying is particularly dependent on the applied boundary-layer modelling approach since the major part of the boundary-layer resistance to heat and mass transfer (thus also the CTCS) is located in the lower part (e.g. [124,125]). Here, wall functions (WFs) are often preferred over low-Reynolds number modelling (LRNM) for increased computational economy and easier grid generation: WFs, which model the flow quantities in the boundary-layer region by calculating them by means of semi-empirical functions, avoid resolving the boundary layer explicitly, which requires an extremely high grid resolution for LRNM at high Reynolds numbers. As such, LRNM is not practically applicable for several complex 3D configurations $[115,126]$.

WFs however produce less accurate results for complex flow problems and should definitely be avoided when considering convective (heat) transfer [124,126-128]. Nevertheless, they are still extensively used in CFD modelling of drying processes, as identified by the recent literature survey performed by the author above (section 4). Only a limited amount of studies have applied LRNM (e.g. $[46,75,129,130])$ but many studies also do not report the boundary-modelling approach which was applied. Hence future best practice in CFD and modelling in general should be directed towards detailed reporting of the used simulation parameters.

\subsubsection{Particle drying}

CFD has been applied extensively to model drying of moist particles (granular material) or droplets with solid material inside (suspended or dissolved). Both will be referred to as "particles" below. CFD is used here to gain insight in the particle flows and trajectories, dispersion rates, particle drying time, residence time, particle deposition locations and the influence of drying conditions and chamber design on the particle drying process. CFD offers an alternative to experimental laboratory, pilot-plant or full-scale studies, and has the particular advantage that (individual) particle flow and drying behaviour can be monitored at very high spatial resolution. However, such modelling is challenging due to the multitude of physical processes which have to be captured. These include modelling of turbulent flow, particle transport, particle interactions with the dryer walls or with each other (particle agglomeration/ droplet coalescence, [131]) on the one hand, and particle drying kinetics on the other hand, and their mutual interaction. The most popular application of CFD here is spray drying [94].

With respect to turbulent flow modelling, both accurate bulk flow (turbulence) modelling (section 4.1.1) and boundary-layer modelling (section 4.1.2) are required to capture particle transport as well as particle deposition on walls, both discussed earlier. With respect to boundary-layer modelling, LES becomes too computationally expensive and hybrid RANS-LES modelling seems a more logical choice [98].

For modelling particle transport and particle interactions, two two-phase approaches are mainly applied (e.g. [132-134]). In the Euler-Lagrangian (E-L) approach, the gas phase is treated as a continuum but the trajectories of individual particles are calculated separately. In the Euler-Euler (E-E) approach on the other hand, the gas and particle phases are modelled as two interpenetrating continuous media, thus as a two-phase mixture. The performance of both approaches is compared in Table 1 for various CFD modelling criteria, as compiled from several sources (amongst others, [98,132,133,135-137]). Though the E-E approach often has a significant computational benefit, the intrinsic richer physics of the L-E approach and its wider range of applicability make it the preferred choice for spray drying [98,101,132].

Accurate modelling of the particle/droplet drying kinetics, thus intra-particle heat and mass transport, is also crucial as it can be the limiting factor for the particle drying rate, namely if the resistance to moisture transfer within the particle dominates over the boundary-layer resistance (CHTCs). The most common modelling 
approaches are [138]: the characteristic drying curve, diffusion-based models, receding plane models as well as more recent population balance models [139-141] and the reaction engineering approach (REA, [142-144]). The latter is recently becoming more popular and is argued to be very promising since it combines a relatively low computational effort with increased accuracy $[95,145]$. Population balance modelling is particularly suitable to deal with breakup and agglomeration of particles [139]. Note that the coupling between the particles (discrete) and gas (continuous) phase with respect to the drying kinetics can be one-way or two-way.

There are still particular challenges with respect to modelling drying of particles and droplets. Research efforts should particularly be directed towards improved modelling of: turbulence [98]; 3D unsteady transient cases instead of 2D steady ones [97,98,146]; particle interactions, including particle agglomeration or droplet coalenscense [131-133]; wall interactions/deposition [147]; particle drying kinetics [138,145,148], particularly the spatial variation of the moisture content within particles $[98,138]$, the hindering effect of the solids inside droplets on their drying due to shell formation $[98,149]$ and the coupling of particle drying models to CFD [140]; and impact of various particle shapes and sizes on particle drag and convective heat and mass transfer (correlations) [94]. In addition, one could also think of including models for thermal degradation and nutritional quality of (food) particles to enable particle quality predictions as well, though this is left quasi unexplored to date.

Furthermore, additional efforts could be directed towards the implementation of particle or droplet drying in (commercial) CFD software, which now still involves tweaking of the software by the user with user-implemented models to account for particle drying kinetics, particle interactions or turbulent dispersion, amongst others. The aforementioned contributions should provide important steps towards more reliable, quantitative predictions of particle drying, which are still often considered to be rather qualitative [94]. In addition, it is also evident that experimental validation will remain paramount for the further development and use of CFD for particle/droplet drying [146]. Lack of such data is even argued to hinder CFD progress in this area [97].

\subsection{Multiphysics modelling}

\subsubsection{Conjugate air-material modelling}

Modelling the convective heat and mass exchange of a porous material with its environment during drying can be done in several ways [75]: (1) Well-established CTCs from literature are used, which have been determined analytically or (semi-)empirically for simplified configurations, such as flat plates. This approach is called nonconjugate since the air-side transport is not explicitly resolved. It is a rather simplified way of dealing with convective exchange, but it is still common practice in drying technology (e.g. [150]); (2) Case-specific CTCs are determined, which for example include a spatial CTC variation, as obtained from separate flow-field calculations using CFD (e.g. [116], see section 4.1.2), or a temporal CTC variation, by incorporating a dependency of CTCs on the moisture content at the surface (e.g. $[151,152])$. This is referred to as a semi-conjugate approach; (3) The heat and mass transport in the air and in the porous material are solved simultaneously in a transient way, which is called conjugate modelling.

Conjugate modelling circumvents imposing (simplified/constant) CTCs as boundary conditions at the air-porous material interface in drying simulations. In addition, it allows to determine them a-posteriori, by which their spatial and temporal variability can be unveiled (e.g. [46], Figure 5). As the air-side transport at the interface is explicitly solved, this modelling approach is inherently more accurate and does not require the use of the heat and mass transfer analogy, which can have a significant added value for complex flow problems. For this reason, 
conjugate modelling strongly gained popularity in the past decade (Figure 4). A recent review of conjugate modelling for drying processes was given by Defraeye et al. [75]. Lemus-Mondaca et al. [153] dealt with conjugate modelling within the broader context of thermal processing of food. An overview of the studies which applied a conjugate or semi-conjugate approach for applications related to drying, to the current knowledge of the author, is given in Table 2 .

There are a few reasons why the conjugate approach has not yet replaced the use of (more simplified) CTCs in drying modelling. First, the physics to be solved in the porous material and the air flow (and associated time scales) are significantly different (Figure 3). Secondly, the most popular computational method to solve transport in each discretised domain (air or material) also differs: fluid-flow modelling with CFD predominantly relies on finite volume modelling $[101,109]$, whereas heat and mass transport in porous materials together with mechanical deformation is commonly modelled using FEM [20]. These differences have hindered the (commercial) development and availability of dedicated software for such conjugate modelling.

Apart from some exceptions (e.g. COMSOL Multiphysics ${ }^{\circledR}$ ), most existing commercial or in-house software is not developed for solving for both at the same time nor in a computationally efficient way. As such, conjugate models often have to be explicitly implemented, which can be done in several ways (see Table 2). First, a model for coupled heat and mass transport in porous materials can be implemented within existing CFD software. Commercial CFD software packages however often do not allow a (straightforward) implementation of such a model [94], amongst others due to limited access to the code. Second, a CFD code can be implemented in an existing drying model for porous materials. As the latter is often based on FEM, the CFD code can run much less computationally efficient and/or stable (than FVM), which could become an issue for complex 3D flow problems. Third, an existing (commercial) CFD code can be coupled to an existing porous material model in an explicit way, i.e. by exchanging of boundary condition information at the interface $[46,154]$.

Due to limited availability or computational efficiency of such computational tools, the majority of the conjugate studies are rather academic, for simplified 2D geometries and laminar flow, and rely (fully or in part) on academically developed codes (see Table 2 and [75]). With respect to commercial software, COMSOL Multiphysics ${ }^{\circledR}$ (previously FEMLAB) clearly dominates. Since COMSOL’s CFD capabilities have been extended significantly over the past years, amongst others by including LES, this software is expected to become even more attractive for solving conjugate drying problems and the underlying multiphysics involved. The availability of userfriendly multiphysics software which can deal with complex 3D conjugate problems, including unsteady turbulent flow, opens perspectives for both researchers and industrial users. Such tools could increase the use of conjugate modelling to optimise industrial drying processes. For now, the (programming) effort that has to be undertaken is still a bridge too far for many (industrial) modellers.

Modellers should however acknowledge that the accuracy gained by conjugate modelling does not always outweigh the additional modelling effort or computational cost, even with dedicated user-friendly software. In specific cases, the use of simple CTCs can already be sufficient as detailed below. The level of complexity with which the (air-side) convective exchange has to be accounted for is actually strongly dependent on the moisture transport characteristics of the porous material. When moisture transport inside the porous material governs the drying kinetics, i.e. during the decreasing drying rate period (DDRP), the sensitivity to the convective boundary conditions can be very limited $[15,46,75,155]$. Hence a reduced accuracy of air-side transfer predictions by using CTCs instead of conjugate modelling does not necessarily disturb a reliable simulation [156]. Several foods dry predominantly in the DDRP, as the CDRP is limited or even non-existent $[48,157]$. Here material characterisation related to liquid and vapour transport within the product should deserve more attention instead of accurate modelling of the convective boundary conditions. Before embarking on a conjugate modelling study, which 
implies CFD modelling, it is advised to perform a-priori a sensitivity analysis with respect to the relevance and the required degree of complexity of the convective boundary conditions. However, for strong non-isothermal drying in particular, conjugate modelling with respect to heat transfer is always advised [75] since: (1) convective heat exchange affects the latent heat supply needed for evaporation; (2) the boundary-layer resistance for heat transfer (i.e. the inverse of the $\mathrm{CHTC}$ ) often lies much closer to the heat transfer resistance of typical porous materials, compared to those for mass transfer, by which heat transport inside the material will be less dominant compared to that in the boundary layer; and (3) mass transfer in porous materials can be thermally driven (Figure 3).

\subsubsection{Coupled moisture-mechanics}

For soft materials such as many foods or wood, dehydration is accompanied by structural changes of the porous matrix. The water loss induces deformation, such as shrinkage or warping, but also internal pore development, case hardening of the product shell and even damage by cracking. These have an (often negative) impact on product quality and, for food products in particular also on rehydration capacity or sensory properties (e.g. structure, texture, mouthfeel), which determine palatability, consumer acceptance and marketability. Furthermore, these structural changes, which take place at multiple scales, alter the moisture transport properties of the material dynamically during the drying process itself $[158,159]$, and affect thereby the drying kinetics and the resulting drying time.

For these reasons, the structural changes to the porous material and their impact on the dehydration process should be included as well when modelling drying processes of soft (biological) material. Usually, only the hygromechanical deformation (shrinkage) is modelled and implies deformation driven solely by moisture removal, thus the absence of other external forces. A detailed review of drying models which account for hygro-mechanical deformation can be found in [60], which identifies its increasing use in drying modelling. These models should capture the most relevant physical processes with respect to dehydration-driven deformation. At high moisture content and small deformations, soft materials typically exhibit a viscoelastic, rubbery behaviour. Here, the water removal due to drying is quasi entirely compensated by a decrease in volume of the material, by which a linearly proportionality relationship is found between volume change and water content, which is called free shrinkage [160]. At lower moisture contents and larger deformations, soft materials often behave more rigid (glassy), where the porous matrix exhibits a certain resistance to volume reduction. As such, the volume reduction is smaller than the amount of water removed and the internal porosity will increase, leading to a non-linear relationship between shrinkage and water content [161], which is called non-free shrinkage. Next to hygrostresses, also thermal stresses and associated deformations can be induced in strong non-isothermal conditions.

Models of multiphase transport in porous media which include hygro-mechanical deformation are usually existing models for heat and mass transfer (without deformation, see section 3 ) which are simply extended to include shrinkage $[60,66,67,162,163]$. The coupling between water transport and deformation can be (see Figure $6,[60]$ ): (i) one-way, i.e. where water transport induces (hygro-)mechanical deformation but is itself not affected by shrinkage, by which the same equations as non-shrinking models can be used (e.g. [164]); (ii) two-way, where the (hygro-)mechanical deformation also affects water transport, and vice versa [165-170]. The coupling approach becomes apparent from the water transport equations, i.e. whether or not shrinkage is included here. The most common approaches for modelling hygro-mechanical deformation as well as water transport (for two-way coupling) are discussed separately below and are depicted schematically in Figure 6. 
Hygro-mechanical deformation is modelled using two approaches. In a first approach, a relationship between shrinkage and moisture content is determined, empirically or based on more fundamental principles, of which a review can be found in [160]. These shrinkage models allow a straightforward prediction of the deformation, namely by means of a simple algebraic equation, by which they are very popular. In a second approach, shrinkage of the solid matrix is explicitly modelled by solving its momentum balance. This approach is inherently more complicated as it requires solving a partial differential equation and determining relevant mechanical material properties. Here, predominantly small deformations, assuming linear (visco-)elasitic materials, are modelled. Drying of several soft materials, such as many foods, is however accompanied by large deformations (>1-2\%, e.g. [171]), which require nonlinear (elasticity) theory to be used, for example assuming a hyperelastic material $[45,164]$.

Modelling such hygro-mechanical deformation by using conventional solid mechanics models and software has been impeded by the intrinsic additional modelling effort for including water transport [172,173]. Furthermore, such advanced drying modelling is complicated by the fact that the mechanical (and water transport) properties, which serve as an input for the model, can change significantly during drying, which ideally requires an additional effort with respect to material characterisation (section 4.3).

When modelling water (and heat) transport in the material, the impact of shrinkage is rarely accounted for [60], implying a one-way coupling (Figure 6). As such, phenomena as changing water transport properties as a function of deformation state, or water transport driven by stress-induced water pressure build up within the solid matrix during rapid deformation cannot be captured. Though a two-way coupling is rarely considered to date, it might be the way to go in future to study and unveil phenomena currently not feasible with one-way coupling. Such twoway coupling can be included in several ways in the model, of which some are depicted in Figure 6 . In addition to deformation, other dehydration-induced structural changes, such as mechanical damage by surface cracking, should deserve more attention with respect to modelling as they affect the water transport during drying but also the final product quality (see $[174,175])$.

\subsubsection{Perspectives towards integral multiphysics models for drying}

Modelling heat and mass transport in materials during drying can also be coupled to models for physical processes other than air flow around the product (conjugate, section 4.2.1) or (hygro-)mechanical deformation (section 4.2.2). The most known example here is probably drying modelling by means of microwave heating [28,176-179], which is often performed in combination with convective or infrared drying. In principle, any other physical process can be included in a multiphysics model, as long as the software permits its implementation and model calibration and validation are successful. Within the field of food engineering, the group of Datta is at the forefront of such multiphysics modelling of dehydration processes, (for references see section 4.2.1-4.2.3).

Future perspectives in multiphysics modelling should be directed towards developing more complete multiphysics models for drying, i.e. models which couple heat and mass transport within the material simultaneously with multiple other physical processes (e.g. deformation, airflow, radiation), instead of with only a single one (e.g. as in conjugate modelling, section 4.2.1). Particularly for food, such next-generation dehydration models should also include (bio)chemical or biological (degradation) processes to be able to address quality and safety parameters. Examples of such processes are thermal degradation, nutrient and enzyme loss, organoleptical quality changes (color loss, flavour/aroma loss, texture) or microbial (de)activation(e.g. $[55,180]$ ). These processes have been typically modelled stand-alone [181] and coupling with multiphysics (dehydration) modelling has been limited for food drying, but is more established in other thermal food processing operations (e.g. sterilisation, [28,74]). The 
use of such overarching integral models is not reported to date for drying applications, to the best knowledge of the author.

Such integrative models are indispensable to progress beyond the current state-of-the-art in drying process optimisation. The main reason is that such optimisation often results in various conflicting interrelations between process parameters and process objectives, resulting in complex trade-offs [182]. A typical example for food is how an increased drying rate, induced by a higher temperature or airflow rate, has a beneficial effect on throughput, microbiological lethality and shelf life but can reduce food quality by nutrition loss, surface cracking or case hardening and can also increase energy consumption, operational costs, food waste, losses by off-spec products and the embodied energy therein. Identifying these complex and often conflicting interrelations is critical for optimising this multi-objective problem, and will ask for an unprecedented integrative modelling approach. In the first place, this requires that all relevant physical processes are resolved simultaneously in a coupled way, but if necessary also the relevant (bio)chemistry and biology. Solving for the latter is less challenging as models for deteriorative (bio)chemical and biological processes (e.g. vitamin degradation in food) can be successfully described by simple kinetic models [181]. Development of such integral models is thus very timely and will allow to unveil these multivariate interrelations. In addition, when integrated in a user-friendly software environment, their increased realism can make modelling of drying processes much more attractive [28]. In a next step, these models can also be used as a basis for an even more overarching evaluation of the drying process, namely by including energy consumption and energy quality and other drying process parameters (such as product losses, off-spec products, total throughput, process economics, etc.), as discussed in section 5.4.

Developing and running such coupled, integral models will definitely be challenging for drying engineers given the current difficulties encountered when coupling dehydration with airflow or deformation (section 4.2 .1 and 4.2.2). Specific bottlenecks include the computational cost associated with modelling realistic three-dimensional dryer configurations, a user-friendly problem setup and simulation, and straightforward implementation of the relevant multiphysics processes. A proper software environment is of key importance here. Finally, a strong coupling between the physics to be solved (e.g. heat, mass, mechanics) is present via the transport equations and material properties (e.g. a dependency on moisture content or temperature $[20,46]$, Figure 3 ) and dealing with the resulting complexities for coupling, implementation and simulation is a major challenge. For these reasons, such integral models in drying technology are envisaged to emerge first within academic environments and for academic studies (e.g. drying of a single product in 2D). In addition, these advanced models are currently the less preferred choice with respect to model-based optimisation of food processes, compared to more simplified modelling approaches $[16,182]$. The reason is their high computational cost, as optimisation algorithms involve evaluation of many different scenarios to converge to an optimal solution.

\subsection{Multiscale modelling}

The products to be dried are inherently multiscale assemblies (see section 2.2), where observations during drying at the macroscale (e.g. shrinkage) actually originate from changes at microscale level $[91,92,183]$. A deeper understanding of drying at product level (macroscale) by means of modelling, but also better model accuracy, might be sought by explicitly accounting for transport phenomena at lower scales in the model as well, to some degree of complexity.

Two approaches can be applied for this purpose: cross-scale modelling and multiscale modelling. Cross-scale modelling indicates that a large range of length scales is included within a single computational setup (e.g. $[119,121])$. As the range of length scales that can be included in most models is rather limited, due to the high 
computational cost associated with resolving all of them simultaneously, this approach is rarely pursued in computer-aided drying process engineering. Instead, multiscale modelling is preferred. Here, the relevant transport phenomena at each spatial (and temporal) scale of interest are calculated separately by a submodel. Often, each of these submodels is based on different modelling principles, techniques and even software. As such, co-simulation is often applied for multiscale modelling, i.e. coupling two or more different software, instead of integrating all models into a single software environment. The coupling of these submodels, by exchanging information between them, is the essence of a multiscale model. A multiscale model usually outperforms a full cross-scale modelling approach with respect to the range of length scales that can be included and the computational cost, which does not necessarily increase steeply with the amount of length scales (thus submodels). On the other hand, the performance and accuracy of a multiscale model heavily relies on an appropriate coupling of the submodels.

Such a multiscale coupling can be one-way (sequential). Here, calculations are performed independently at one scale by a particular submodel, and relevant information is subsequently transferred to a higher scale (upscaling, homogenisation, coarse-graining, [184]) or to a lower scale (downscaling, localisation, fine-graining). A wellknown example here is the determination of apparent macroscopic material (transport) properties (and their dependency on temperature, moisture content, etc.) via homogenisation from numerical simulations at the microscale, i.e. at the scale of a REV (e.g. [185]). One-way coupling allows to link multiple scales (i.e. >2) in a straightforward way [186]. The validity and applicability of such sequential coupling decreases if too many dependent variables have to be accounted for [184] and if time scales overlap, as then the thermodynamic equilibrium condition of the phases is not satisfied locally in a REV. In this case, the lower-scale transport (e.g. microscale) depends not only on the higher-scale transport, but also on the history of the latter $[59,187]$.

In such cases, a two-way (parallel, concurrent) coupling is more appropriate. Here, submodels at two or more scales are solved simultaneously and information is exchanged [187]. Hereby, temporal changes of variables (e.g. temperature) and gradients over a REV, e.g. at the microscale, are explicitly resolved [59]. The most well-known example of two-way multiscale modelling is probably CFD modelling of particle/droplet drying, where the flow in the entire dryer as well as the drying behaviour of individual particles is resolved simultaneously $[146,188,189]$. The term "multiscale" is however not often used in this context. Other studies using two-way multiscale coupling for drying are, amongst others, [190-198]. Even though such two-way coupling is time consuming, particularly if more than two scales are involved, it is still more computationally economical than cross-scale modelling. For particle drying, the latter would imply that the boundary-layer flow around each individual particle has to be resolved, which is currently not feasible.

Multiscale modelling has distinct advantages. First, it allows to study transport processes at all scales of interest, which is difficult or even not possible with experimental techniques at the lowest scales. Prerequisites are that a reliable, validated computational model is available at each scale and that all scales can be coupled appropriately. Second, different aspects of the drying process, such as drying time, product quality and dryer energy usage, can be addressed and optimised at the same time, where each of these aspects is associated with a specific scale and model (see $[190,191])$ : changes in material texture and structure at the microscale; drying time and product quality (cracking/warping) of individual products at the macroscale; energy consumption at the dryer scale.

Despite its potential, multiscale modelling has been applied rarely in drying technology and mainly by academics [30]. The group of Perré is at the forefront in this field [59,187,190-192]. Nevertheless, multiscale modelling is envisaged to protrude more in drying R\&D in the coming decades (Figure 4) due to its unique ability to incorporate the very rich physics at the lower scales, especially regarding microstructure, into models at the macroscale and dryer scale. The main challenge while developing such multiscale models is the (one-way or two- 
way) coupling of the submodels which describe the relevant physics at each scale. The coupling procedure and its numerical accuracy are critical for successful multiscale modelling and should be verified. Particularly for two-way coupling, an important aspect is the sensitivity to the time step, where the coupling time step between submodels and the time step used in individual submodel simulations can be taken different [187]. In addition, efficient coupling and information exchange between submodels, which often use different software, is a point of concern. Another major hurdle faced when performing multiscale modelling is that the user is expected to have expertise of the modelling methods in each submodel that is used and of the underlying physics at each scale, which is far from evident. The typical case-specific nature of multiscale models, induced by the large differences in material characteristics, their microstructure (Figure 2), the transport processes therein, the submodel types and different software used, restricts to some extent a generalised modelling framework.

For a broader background on the multiscale modelling paradigm, the reader is referred to textbooks, since multiscale modelling has been more developed in other fields of research, compared to drying technology $[199,200]$.

\subsection{Material properties \& modelling}

Continuum models (for meso-, macro- and dyer scale) aim to include all relevant physics governing the drying process in order to allow realistic drying predictions and thereby make them a viable alternative to experiments. They however critically rely on material properties, such as thermal, mass transport, mechanical, rheological, kinetic (chemical and microbiological changes), dielectric and radiative properties [28]. These material properties, including transport-related properties [201], are usually determined by experiments, but also by theoretical predictions or numerical simulations $[184,202,203]$. The latter implies simulations at the scale of the REV, e.g. pore network simulations. Such simulations are becoming more popular, particularly within the framework of multiscale modelling (section 4.3), since the dependency of a property on various parameters (temperature, moisture content, etc.) can be evaluated rather easily and in a very detailed way. These property data are typically turned into a model equation [29], describing for example its dependency on temperature, which can be directly implemented in a macroscopic continuum model. These "property models" should have low complexity, a limited amount of input/dependent parameters and should be determined for a representative range (e.g. temperature). Their accuracy is typically below $10 \%$ for most properties [29]. Though such material properties are key determinants for the accuracy of a drying simulation, modellers in research or engineering often cannot find or acquire such material property data in sufficient degree of detail within a reasonable timeframe or at a reasonable cost, for several reasons.

First of all, they are not readily available or even not determined for many products, due to continuously emerging new products and the large amount of materials currently available, which is particularly the case for biological materials such as foods [48]. For several properties, for example those related to water transport, measurements are very complex, time consuming and require specialised equipment and expertise $[19,204,205]$. Though such specialized characterisation is often undertaken by academics, industrial users are less likely to spend this time while performing a modelling study.

Secondly, material properties change during the drying process, as they are dependent on multiple parameters such as temperature, moisture content, structure (deformation, porosity) and the interaction of product components with water $[48,183,206]$. This multivariate dependency at different stages of the drying process again implies an additional characterisation effort. 
Thirdly, variability on these material properties is induced by material heterogeneity in manufactured materials but particularly in natural products, due to intrinsic biological variability. Additional variability is introduced by the measurement accuracy of the test setup (experimental uncertainty) and differences in measuring equipment, measurement protocol and data postprocessing between different laboratories [207-210]. This variability implies that sufficient repeats have to be performed to determine representative (mean) property data and to quantify the variation, which is a very tedious procedure.

Acquiring appropriate material property data thus still often forms a bottleneck in continuum modelling [29]. The required expertise and equipment, the need for many repeats and the multivariate dependency of the material properties often pose a serious barrier to drying engineers, which leads to a severely downsized material characterization or the use of values from literature. Appropriate material data, and associated predictive equations or models [29], can currently be considered as one of the largest needs in drying modelling. Steps towards their widespread availability are imperative for making modelling more useful and attractive for drying engineers [28]. Extending current material property databases, amongst others those built-in in commercial software, plays an important role here. Furthermore, future efforts should be directed even more towards straightforward numerical modelling of properties, by means of homogenisation, as in-silico experiments have the distinct advantage that a large amount of repeats can easily be performed, the multivariate dependency on drying parameters can be determined and experimental errors are non-existent.

Apart from experimental or numerical acquisition of these properties, the propagation of the variability (or uncertainty) on the material properties into the numerical simulation results is also a key aspect to be addressed, as it can have a large impact on the outcome of drying process calculation (Figure 7). The stochastic Monte Carlo method has been successfully applied for this purpose ([207], Figure 7). The Monte Carlo method is however computationally expensive, as it requires about a few 1000 simulation runs. More computationally-economic probabilistic perturbation methods [211,212] have also been used for drying [213]. They are based on the analysis of the propagation of a small perturbation of the stochastic variables into the solution. Apart from for material properties, such stochastic methods can also be applied to analyse the impact of varying process conditions (airflow rate, initial moisture content, etc.), as done by $[190,214,215]$.

Though the critical impact of such material property variability on the drying rate was already identified (e.g. [207]), such stochastic modelling studies are rarely undertaken for drying, mainly due to the additional time and effort required. Accounting for such variability/uncertainty propagation is however envisaged to be one of the most important steps to be taken in the future to allow more reliable and realistic drying predictions. In any case, simple property sensitivity analysis is always strongly recommended.

\section{$\underline{\text { 5. Future developments }}$}

Specific future perspectives for each of the advanced computational methods for modelling drying of porous materials were detailed in the respective sections above. Below, more general, overarching future developments and challenges in the context of such advanced modelling are briefly discussed.

\subsection{Best practice and quality control}

CFD is often referred to as "Colourful Fluid Dynamics", implying here that with CFD, one can generate nice flowfield visualisations but not necessarily realistic ones. Though this terminology is mainly applied by modelling sceptics, limited model accuracy can indeed be masked to some extent by CFD software and its graphical output. Such suspicion with respect to the accuracy of advanced computational methods in general is not entirely unjustified as a large variety of errors can be introduced by the user [109]: (1) physical modelling errors, related 
to simplifications in the computational model, compared to reality, but also those related to the turbulencemodelling and boundary-layer modelling approaches, the imposed boundary conditions or the implemented submodels; (2) discretisation errors, related to the spatial discretisation (computational grid) and temporal discretisation (time step); (3) iterative convergence errors, i.e. when the simulation is ended.

Nowadays, the step towards advanced modelling of drying processes is becoming ever smaller for researchers and industrial users, amongst others due to more user-friendly or open source software. Nevertheless, (new) users should not take modelling lightly and should be aware of the errors they can introduce by bad practice and misuse of modelling techniques, as their impact can be substantial [100]. Dedicated quality control is required while performing a modelling study, even though this brings along additional work. Within the CFD community in particular, there has always been an attitude towards performing detailed quality assurance of simulations, which led to the development of several best practice guidelines (e.g. [109,134]).

Similar guidelines, specifically oriented towards modelling in drying technology, are particularly timely since the modelling community is growing fast here. Such best practice in drying modelling is of key importance to increase the credibility and trust of modelling and to refute criticism, but also to facilitate training and dissemination of computer-aided drying process engineering to both engineers and academics.

Finally, modellers will always have to compromise between modelling accuracy and complexity on the one hand and computational restrictions to time or resources on the other hand. Modellers should always acknowledge, and preferably even quantify, the impact of their modelling approaches and simplifications on the accuracy of their results [216], particularly since their choices are often driven by computational restrictions to time or resources, instead of modelling accuracy.

\section{$\underline{5.2}$ Model validation}

The need for detailed experimental data which can be used to validate advanced numerical simulations is widely acknowledged in the drying community. Such validation data is often not available for the specific case of interest $[6,75]$, or is limited (e.g. with low spatial or temporal resolution, only gravimetric data, etc.). These limitations are the main drivers for research towards more advanced experimental techniques, such as non-destructive imaging, and the development of new drying equipment (e.g. novel laboratory dryer tunnels) to monitor and study drying processes.

Particularly experimental techniques based on non-destructive imaging show promising perspectives for more detailed validation of numerical models. The most popular ones are presented in Table 3 together with a few applications. A more in depth discussion can be found in [217] and [218], amongst others. There is a strong relation between the attainable spatial resolution in the image and the image acquisition time, which both depend on the used technique and the type of device used (e.g. laboratory, synchrotron or clinical X-ray) [93]. The high spatial resolution of some techniques (e.g. $<1 \mu \mathrm{m}$ for $X$-ray) even allows to study transport processes down to the microscale level. A particular bottleneck for some drying processes are the time scales, which are strongly problem specific and can become very low (e.g. spray drying). As such, time-resolved measurements can become difficult (e.g. 4D tomography). This continuously pushes researchers towards developing ultra-fast imaging (e.g. neutron: [219]; X-ray: [220,221]; MRI: [222]).

Examples of novel equipment development are for example acoustic levitation or a magnetic suspension balance for studying drying of single particles or droplets [223], a device to measure water activity at product surfaces during drying [224] and a sensor to measure the CHTC at high spatial and temporal resolution [225]. 
Future developments are expected towards better integration of non-destructive imaging techniques with the experimental equipment [226], and optimisation of this ensemble specifically for drying applications. An example is the use of a (mini) laboratory drying chamber which is designed specifically for the non-destructive imaging setup in which it is to be used [227], and which can include even environmental control with the possibility to rotate samples for tomography [228]. Another option is customisation of the imaging system specifically for the test setup [229]. Such customisation and integration should further increase the added value of non-destructive imaging techniques to study drying processes and particularly to validate numerical simulations. Since such experiments are very time-consuming and costly to develop and execute, detailed validation is still predominantly performed in academics, and more simplified validation is performed in industry [28].

\subsection{Geometrical models}

The computational methods discussed in this review require a geometric model of the product to be dried and/or of the dryer topology (e.g. drying chamber). At the dryer scale and macroscale, such 3D geometrical models can usually be generated by CAD modelling. For very complex and irregular product shapes or at the lower scales, CAD generation of such models is often more challenging, for example for biological materials such as food. Alternatives are based on both destructive (e.g. microtome, [86]) and non-destructive 3D imaging techniques (Xray (micro-)CT, MRI, laser scanning, etc., [93,230], see also Table 3). They allow explicit imaging of the exterior and/or interior structure of materials at sub-millimetre resolution (e.g. wood: [231-233]; plant organs: [234,235] ; stone: [236]), and even down to a few hundred nanometers for some techniques (e.g. synchrotron X-ray sources, [234]). 3D high-resolution CAD models can be generated subsequently from the images by reverse engineering.

Such imaging techniques are becoming more popular for geometric model generation for drying modelling purposes, amongst others due to easier accessibility to these technologies. They have been used, for example, to generate computational models for drying of corn kernels [168], drying of granular media [237] and water transport in wood vessels [86]. Apart from generating geometric models for simulations, some of these imaging techniques are especially useful to generate the appropriate initial or boundary conditions for simulations, for example the initial moisture content distribution inside the material from neutron imaging [238].

\subsection{Integrated modelling towards energy-smart drying}

Drying process evaluation and optimisation should ideally cover all key aspects of the process, namely:

- Product quality (e.g. product heterogeneity, critical moisture content, case hardening, nutritional content) and product losses (e.g. off-spec products) but also product (food) safety.

- Individual product drying time and total throughput.

- Process/equipment design, operation and control.

- Energy use and consumption (e.g. reduce/recuperate waste heat, avoid excessive energy use by overdrying, pre-treatments such as dewatering), the indirect energy loss embodied in the product losses and recently also energy quality (exergy, [239-243]).

- Process economics [3].

These aspects are all strongly coupled. An in-depth understanding of the dehydration process of the product is essential to enhance drying processes as it plays a key role in all of these aspects. Process optimisation is thus a 
multi-objective problem with various complex interrelations between process parameters and process objectives, resulting in multiple trade-offs [182], as illustrated below.

As an example, overdrying of the product does not only reduce product quality, but also increases energy costs, as more water is evaporated (latent heat) and drying times are longer. Another illustration of this strong coupling is that around $38 \%$ of the total energy consumed by the food chain is embodied in the global annual food losses $[38,244]$. Furthermore, product pre-treatments prior to drying aim at saving energy [11], for example via dewatering, by which the amount of water to be evaporated is reduced, or via partial destruction of the material microstructure, by which water transport inside the material is facilitated, leading to increased drying rates. A final illustration is the use of renewable energy, namely solar drying, as an alternative to conventional hot-air drying. Though the energy consumption is reduced, the product quality can decrease significantly due to radiation-related degradation (e.g. surface cracking, nutritional content, discolouration) if products are exposed to direct sunlight (e.g. $[56,245]$ ). Even indirect solar drying, i.e. using solar radiation just to preheat the drying air, is not ideal due to the systematic (day-night cycle) and stochastic fluctuations (cloudiness) in incident radiation, also leading to partial rehydration of the food. As such, thermal storage systems, auxiliary heating or incorporating desiccants is required to keep the total drying time within limits and thereby avoid associated spoilage of the product $[246,247]$. Several upcoming, more energy-smart drying technologies should thus be evaluated in close relation with dehydration of the product itself, such as osmotic dehydration, heat-pump assisted drying, use of zeolites, solar drying, superheated steam drying, hybrid and multistage drying, (partial) air recirculation/recuperation and others (see [7,11,12,243,248-251]).

From the examples above, it is clear that energy is closely intertwined with the drying technology used and the processing conditions, the product quality and its drying behaviour, but also with the amount of embodied water and water transport in the material [3]. In a more general context, the close coupling of energy with food and water was recently presented as the energy-water-food nexus concept [252,253], and is presented as a novel paradigm to increase efficiency in each of these sectors by improving synergies between them. Likewise, a casespecific nexus concept can be put forward for drying processes, namely the product-energy-water-process nexus, as illustrated in Figure 8. Examples of the complex coupling between all its sectors were discussed above. Below, a first outlook towards the application of a nexus concept for advanced modelling of dehydration processes in particular is given.

The advanced numerical modelling methods used to analyse drying of porous materials, discussed in this review paper, mainly focus on product quality and drying time/throughput within the context of optimising dryer design, drying conditions (operation) or process control. As mentioned, the future development of integral models (including multiphysics, biochemistry, biology) should aid in identifying the complex interrelations between different influence factors of the drying process (section 4.2.3), which should allow to take important steps towards next-generation drying technology. Though such integral models would already allow to cover large parts of the drying nexus (Figure 8), the energy (and exergy) aspect is rarely included in such advanced dehydration modelling $([99,254]$, section 4). Though dedicated energy-optimisation models for dryers exist, which have their own software tools, the product itself and its drying behaviour are modelled quite simplified $[15,250,255]$, which prevents to cover some parts of the drying nexus in the models.

Future efforts in the advanced computational methods mentioned above (section 4), which rely mainly on multiphysics models, should therefore be directed towards integrating energy consumption and energy quality of the drying process, as well as other parts of the drying nexus (Figure 8), in the respective models and subsequent process analysis. Similar to the multiscale modelling paradigm, which recently gained a lot of popularity in drying modelling (Figure 4), such integrated "nexus" modelling can also become a useful paradigm for developing next- 
generation drying technology as the resulting interdisciplinary synergy can improve efficiency of all sectors of this nexus. Such nexus modelling can be done within a single (multiphysics) software environment but also by coupling different programs (co-simulation). A recent step towards such an integrative approach was done by Perré et al. $[190,191]$. They used a multiscale model to combine detailed modelling of the product drying process (wood) together with energy consumption of the drying kiln, which allowed to evaluate different drying technologies from both an energy as well as a product quality (i.e. final moisture content) perspective.

Such integrative nexus approaches in computer-aided drying process engineering should allow to produce more energy-smart products (e.g. food, [38]) using more sustainable and green drying technology. On a final note, energy-smart drying is not only critical in an industrial setting, but also for rural applications. For food, losses related to drying in developing countries are often caused by lack of accessibility to energy. The Food and Agriculture Organisation (FAO) of the UN will particularly stimulate future initiatives for energy-efficient, affordable drying technology for rural settings ([256]). 


\section{Conclusions}

This review dealt with emerging advanced computational methods for modelling dehydration of porous materials, which was approached from a combined multiphysics, multiscale and multiphase viewpoint. The advanced modelling methods included computational fluid dynamics (CFD), several multiphysics modelling methods (e.g. conjugate modelling), multiscale modelling and modelling of material properties and the propagation of material property variability into the simulation results. Current needs and challenges were identified for each of these approaches, of which the most crucial ones are summarised briefly.

- Integration of all relevant physical processes, but also biochemistry and biology, into a single integral model is still pending. Such an integral model would imply that heat and mass transport within the porous material is solved simultaneously coupled with all other physical processes which are essential to the drying process and material of interest, such as airflow around the material, (hygro-)mechanical deformation and damage, radiation (e.g. solar or microwave) and (bio)chemical and biological (degradation) processes (e.g. nutrient degradation, colour change, microbiological activity, etc). Such an integral approach is imperative for a realistic assessment of product quality and drying time and their relation to drying conditions, and to identify the complex and often conflicting interrelations between process parameters, which have a multivariate dependency.

- In a next step, these integral models can form the basis for an even more overarching evaluation of the drying process, namely by including other aspects of the drying nexus (product-energy-water-process) as well in the model (Figure 8), such as energy consumption or efficiency and product losses, amongst others. Such an integrated, energy-oriented computational assessment of the drying process is essential to progress to prime product quality and high product throughput together with low energy usage, carbon footprint and better resource efficiency. Adopting a highly interdisciplinary approach is unavoidable here.

- A-priori sensitivity analysis to the drying process parameters and physics is required, before embarking on a coupled multiphysics simulation, as advanced modelling does not necessarily lead to additional accuracy or insight for every case.

- One of the most important lacunas for many advanced modelling methods is the availability of userfriendly (commercial) software specialised for drying applications, which incorporates all relevant multiphysics transport processes involved (plus biochemistry and biology) and which does not require a significant additional programming effort or expertise from the user. Such tools are paramount to bridge the current gap in drying process modelling between research and industry by making it more attractive and accessible and by allowing more straightforward knowledge transfer.

- Obtaining appropriate material properties required for modelling still forms a bottleneck. Reasons are not only the lack of availability of such data, the time and cost related to their measurements and their strong dependency on process parameters and the drying process, but also the (biological) variability between individual products. Evaluating the impact of the propagation of such variability into the simulation results using stochastic methods is also considered to be an essential future focus.

- Model validation is considered as important for evaluating model accuracy as it is for providing confidence to (industrial) users of the performance and capabilities of advanced modelling, and thereby revoking criticism. Another way of increasing the credibility and trust towards modelling for drying processes is rigorous quality verification of the simulations results and establishing associated best practice in this community.

\section{Recommendation}


The future outlook for advanced modelling in drying R\&D is promising. Though such modelling methods are not expected to replace laboratory, pilot-plant or full-scale testing, they can complement them in optimising current dryers and drying processes and in developing novel ones, tailored for the new requirements of the future society. As such, these computational methods can in some cases just give the edge needed to render methods cost beneficial, which is still the sole criterion for industrial implementation. The long half-life of dryers make such efforts towards more energy-smart and environmentally-friendly drying technology particularly worthwhile and timely. Despite the hurdles faced at the moment, advanced modelling of dehydration processes of porous materials is expected to play an increasingly important role in drying technology R\&D in the next decades.

\section{Acknowledgements}

Thijs Defraeye is postdoctoral fellow of the Research Foundation - Flanders (FWO) and acknowledges its support. The author also wants to acknowledge the many in-depth discussions he had with Dr. Peter Moonen on computational modelling of transport processes in porous materials. 
Defraeye T., Advanced computational modelling for drying processes - a review, Applied Energy 131, 323-344. http://dx.doi.org/10.1016/j.apenergy.2014.06.027

\section{$\underline{\text { Tables }}$}

Table 1. Performance of Eulerian-Lagrangian (E-L) and Eulerian-Eulerian (E-E) two-phase modelling methods (particles or droplets) for different CFD modelling criteria. The best approach according to each criterion is indicated (with $\mathrm{x}$ ) and a motivation is provided.

\begin{tabular}{|c|c|c|c|}
\hline Criterion & $\begin{array}{l}\text { E- } \\
L\end{array}$ & $\begin{array}{l}\text { E- } \\
E\end{array}$ & Motivation \\
\hline Particle transport & $\mathrm{x}$ & & $\begin{array}{l}\text { In E-E, the particle time history is lost (velocity, temperature, residence time, particle deposition position), turbulent } \\
\text { dispersion is modelled in a less generalised way (rather relying on empirical coefficients) and interacting jets of sprays } \\
\text { cannot be modelled. }\end{array}$ \\
\hline $\begin{array}{l}\text { Particle drying } \\
\text { kinetics }\end{array}$ & $\mathrm{x}$ & & $\begin{array}{l}\text { E-L allows the heat and mass exchange of individual particles with the flow to be calculated and monitored in a } \\
\text { transient way. }\end{array}$ \\
\hline $\begin{array}{l}\text { Particle-wall \& } \\
\text { particle-particle } \\
\text { interactions }\end{array}$ & $\mathrm{x}$ & & $\begin{array}{l}\text { E-L allows more realistic and more general modelling of wall deposition (sticking, adhesion) and particle bouncing as } \\
\text { well as particle agglomeration or droplet coalescence (cohesion) since individual particles are considered, for example } \\
\text { by considering explicitly the collision dynamics or interparticle forces. E-E is bound to rely on more empirically-obtained } \\
\text { constitutive equations. }\end{array}$ \\
\hline Particle density & & $\mathrm{x}$ & $\begin{array}{l}\text { E-L is only applicable in practice for dilute mixtures as this keeps the computational cost within limits. E-E is in principle } \\
\text { applicable for any particle loading, though it ceases to be valid for very low particle volume fractions (typically below } \\
0.1 \%,[134] \text { ), as the continuum assumption is violated. }\end{array}$ \\
\hline Particle size & $\mathrm{x}$ & & E-E is in principle not justified for large particles. \\
\hline Scale & & $\mathrm{x}$ & E-L is more suitable for small systems as this keeps the computational cost within limits. \\
\hline Computational cost & & $\mathrm{x}$ & $\begin{array}{l}\text { E-L implies a high computational cost since individual particles have to be tracked and transient simulations are } \\
\text { required in order to attain steady-state conditions with respect to particle flow. E-E has in principle a lower } \\
\text { computational cost as it can often be solved in steady-state, but only if the particle size range is narrow. For wide } \\
\text { ranges, the computational cost for E-E can surpass that of E-L since an additional transport equation has to be solved } \\
\text { for each size fraction for E-E. }\end{array}$ \\
\hline $\begin{array}{l}\text { Parallelisation \& } \\
\text { storage }\end{array}$ & & $\mathrm{x}$ & $\begin{array}{l}\text { E-L is less efficient due to the transfer of individual particles across the different parts of the computational domain, } \\
\text { which is decomposed for parallelisation. E-L also requires significantly more data storage. }\end{array}$ \\
\hline $\begin{array}{l}\text { Computational } \\
\text { stability }\end{array}$ & $\mathrm{x}$ & & $\begin{array}{l}\text { E-L is often more stable, thus shows better convergence, and is less susceptible to numerical diffusion errors. With } \mathrm{E}-\mathrm{E} \text {, } \\
\text { refinement of the grid and reduction of the time step can limit numerical diffusion and improve convergence behaviour. }\end{array}$ \\
\hline
\end{tabular}


Defraeye T., Advanced computational modelling for drying processes - a review, Applied Energy 131, 323-344. http://dx.doi.org/10.1016/j.apenergy.2014.06.027

Table 2. Overview of numerical modelling research of drying of porous materials using conjugate convective heat and mass transfer modelling, including software used (ordered chronologically and based, in part, on [75]).

\begin{tabular}{|c|c|c|c|c|c|c|c|c|}
\hline Author(s) & Porous material & $\begin{array}{l}\text { Fluid } \\
\text { flow }\end{array}$ & $\begin{array}{l}\text { Coupli } \\
\text { ng }\end{array}$ & $\begin{array}{l}\text { Fluid flow } \\
\text { modelling }\end{array}$ & $\begin{array}{l}\text { Dimens } \\
\text { ion }\end{array}$ & $\begin{array}{l}\text { Software for } \\
\text { PM modelling }\end{array}$ & $\begin{array}{l}\text { Software for } \\
\text { fluid-flow } \\
\text { modelling (CFD) }\end{array}$ & $\begin{array}{l}\text { Implemented in } \\
\text { same software }\end{array}$ \\
\hline $\begin{array}{l}\text { Chen and Pei (1989) } \\
{[151]}\end{array}$ & $\begin{array}{l}\text { Wool bobbins, brick } \\
\text { slabs and corn kernels }\end{array}$ & - & $\mathrm{FC}^{*}$ & $\operatorname{CTCs}\left({ }^{\mathrm{a}}\right)$ & $1 \mathrm{D}$ & Academic & none & NO \\
\hline $\begin{array}{l}\text { Masmoudi and Prat } \\
\text { [257] }\end{array}$ & PM & Lam. & $\mathrm{FC}^{*}$ & CTCs $\left({ }^{b}\right)$ & $2 \mathrm{D}$ & Academic & none & NO \\
\hline Zeghmati et al. [258] & capillary PM & Lam. & $\mathrm{FC}$ & BL Eqs. & $2 \mathrm{D}$ & Academic & Academic & YES \\
\hline Dolinskiy et al. [259] & Paper & Lam. & FC & BL Eqs. & $2 \mathrm{D}$ & Academic & Academic & YES \\
\hline Oliveira et al. [260] & Corn meal plate & Lam. & $\mathrm{SC}\left({ }^{\mathrm{C}}\right)$ & BL Eqs. & $2 \mathrm{D}$ & Academic & Academic & NO \\
\hline $\begin{array}{l}\text { Oliveira and Haghighi } \\
\text { [261] }\end{array}$ & Wood board sample & Lam. & SC & Nav.-Stok. & $2 \mathrm{D}$ & Academic & FIDAP (1993) & NO \\
\hline Suresh et al. [262] & Brick & Lam. & FC & Nav.-Stok. & $2 \mathrm{D}$ & Academic & Academic & YES \\
\hline Murugesan et al. [263] & Brick & Lam. & SC & Nav.-Stok. & $2 D$ & Academic & Academic & YES \\
\hline $\begin{array}{l}\text { Erriguible et al. } \\
{[154,264]}\end{array}$ & Wood & Turb. & $F C\left({ }^{d}\right)$ & Nav.-Stok. & $2 \mathrm{D}$ & Academic & ANSYS Fluent 6 & NO \\
\hline Kaya et al. [116] & $\begin{array}{l}\text { Rectangular cylinders } \\
\text { (apple slices) }\end{array}$ & Turb. & UC & Nav.-Stok. & $2 \mathrm{D}$ & Academic & Fluent 6.1 & NO \\
\hline Younsi et al. [265] & Wood & Lam. & $\mathrm{FC}$ & Nav.-Stok. & $3 D$ & $\begin{array}{l}\text { FEMLAB } 2.0 \\
(2000)\end{array}$ & $\begin{array}{l}\text { FEMLAB } 2.0 \\
(2000)\end{array}$ & YES \\
\hline Curcio et al. [266] & Cylindrical carrots & Turb. & FC & Nav.-Stok. & $2 \mathrm{D}$ & COMSOL 3.3 & COMSOL 3.3 & YES \\
\hline Younsi et al. [267] & Wood & Turb. & FC & Nav.-Stok. & $3 D$ & ANSYS-CFX10 & ANSYS-CFX10 & YES \\
\hline $\begin{array}{l}\text { De Bonis and Ruocco } \\
\text { [268] }\end{array}$ & Rectangular carrot slice & Lam. & FC & Nav.-Stok. & $2 \mathrm{D}$ & COMSOL (2007) & COMSOL (2007) & YES \\
\hline Lamnatou et al. [269] & $\begin{array}{l}\text { Rectangular cylinder } \\
\text { (apple slice) }\end{array}$ & Lam. & FC & Nav.-Stok. & $2 D$ & Academic & Academic & YES \\
\hline Lamnatou et al. [270] & $\begin{array}{l}\text { Rectangular cylinders } \\
\text { (apple and banana } \\
\text { slices) }\end{array}$ & Lam. & FC & Nav.-Stok. & $2 D$ & Academic & Academic & YES \\
\hline $\begin{array}{l}\text { Chandra Mohan and } \\
\text { Talukdar [117] }\end{array}$ & Rectangular cylinder & Lam. & UC & Nav.-Stok. & $3 D$ & Academic & FASTEST3D & NO \\
\hline Marra et al. [178] & $\begin{array}{l}\text { Rectangular potato } \\
\text { discs }\end{array}$ & Turb. & FC & Nav.-Stok. & $2 D$ & COMSOL (2008) & COMSOL (2008) & YES \\
\hline Defraeye et al. [46] & Mineral plaster plate & Lam. & $F C\left({ }^{d}\right)$ & Nav.-Stok. & $2 D$ & Academic & Fluent 6.3 & NO \\
\hline Halder and Datta [122] & Rectangular potato slab & Lam. & FC & Nav.-Stok. & $2 D$ & COMSOL 3.5a & COMSOL 3.5a & YES \\
\hline Kurnia et al. [102] & $\begin{array}{l}\text { Rectangular potato } \\
\text { slice }\end{array}$ & Turb. & FC & Nav.-Stok. & $2 D$ & Fluent $6.3\left(^{\mathrm{e}}\right)$ & Fluent 6.3 & YES \\
\hline $\begin{array}{l}\text { Lemus-Mondaca et al. } \\
{[152]}\end{array}$ & $\begin{array}{l}\text { Rectangular papaya } \\
\text { slices }\end{array}$ & Turb. & $\mathrm{FC}^{*}$ & $\operatorname{CTCs}\left({ }^{f}\right)$ & $3 D$ & Academic & none & NO \\
\hline
\end{tabular}

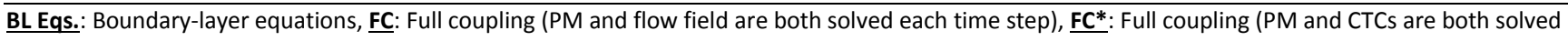
each time step, where CTCs are dependent on PM conditions), FC**: Full coupling (PM and flow field are both solved but in steady state), Lam.: Laminar flow, Nav.-Stok.: Navier-Stokes equations, PM: Porous material, $\underline{\text { SC}}$ : Semicoupled (fluid flow is solved assuming a quasi-steady flow field but transport of 
Defraeye T., Advanced computational modelling for drying processes - a review, Applied Energy 131, 323-344. http://dx.doi.org/10.1016/j.apenergy.2014.06.027

heat and moisture in the flow field is calculated every time step, as well as in the PM), Turb.: Turbulent flow, UC: Uncoupled approach (CTCs from separate CFD simulation and these are afterwards transferred to porous-material model), $\left({ }^{\mathrm{a}}\right)$ : CTCs vary with the moisture content in the decreasing drying rate period, $\left({ }^{b}\right)$ : Local CTCs obtained with superposition method ([271], pp. 175-178) for each time step, $\left({ }^{c}\right)$ : PM and flow field are solved using two different programs where during each time step iterations are performed between both programs until convergence is reached within that time step, $\left({ }^{\mathrm{d}}\right)$ : PM and flow field are solved using two different programs where BC information is exchanged between programs every time step, $\left({ }^{\mathrm{e}}\right)$ : Implemented by means of userdefined functions, $\left({ }^{f}\right)$ CTCs vary over time with the moisture content and temperature. 
Defraeye T., Advanced computational modelling for drying processes - a review, Applied Energy 131, 323-344. http://dx.doi.org/10.1016/j.apenergy.2014.06.027

Table 3. Advanced non-destructive experimental imaging techniques used for monitoring dehydration processes, amongst others within the perspective validation of numerical models, together with some examples of applications.

\begin{tabular}{|c|c|c|c|}
\hline Experimental technique & Application & Measured quantity & Reference \\
\hline \multirow{8}{*}{$\begin{array}{l}\text { X-ray (micro) computed } \\
\text { tomography }\end{array}$} & Drying of wastewater sludge & Deformation, crack formation, moisture content & {$[226,229,272,273]$} \\
\hline & & $\&$ drying rate, (porous) structure of the material & \\
\hline & Drying and (de)sorption of & Deformation (shrinkage and swelling), (porous) & {$[228,232,274-276]$} \\
\hline & wood & structure of the material, moisture content \& & \\
\hline & & drying rate & \\
\hline & Drying of ceramics & Defect formation & {$[277]$} \\
\hline & Dehydration of fruit & moisture content \& drying rate, deformation & [164] \\
\hline & Drying of sand & moisture content & [278] \\
\hline \multirow[t]{3}{*}{ Neutron imaging } & Drying of fruit & moisture content \& drying rate, deformation & {$[227,238,279]$} \\
\hline & Drying of sand & moisture content $\&$ drying rate & [280] \\
\hline & Drying of wood & moisture content & [281] \\
\hline \multirow[t]{8}{*}{ MRI } & Dehydration of fruit in & moisture content $\&$ drying rate & [282] \\
\hline & postharvest storage & & \\
\hline & Drying of a single droplet after & moisture content $\&$ drying rate & {$[283]$} \\
\hline & absorption in porous material & & \\
\hline & $\begin{array}{l}\text { Drying of porous catalyst } \\
\text { support pellets }\end{array}$ & moisture content \& drying rate & [284] \\
\hline & Drying of cement and concrete & moisture content $\&$ drying rate & {$[218]$} \\
\hline & Drying of paper and wood & moisture content $\&$ drying rate & [285] \\
\hline & Drying of paddy rice & moisture content & [286] \\
\hline
\end{tabular}




\section{Figure captions}

Figure 1. Number of papers on drying technology and its relation to energy, food and modelling, obtained from Scopus for selected journals, as a function of time (up to 2013). The cumulative amount is shown and each curve is scaled with the total number of papers, which is indicated between brackets. Details on the exact search queries used to generate these statistics are given in Appendix 1.

Figure 2. Multiscale nature of some products relevant to the drying industry.

Figure 3. Transport processes inside porous materials as well as exchange processes at air-material (or materialmaterial) interfaces. The focus is on processes most relevant to drying.

Figure 4. Number of papers on drying technology and its relation to some advanced computational methods, obtained from Scopus for selected journals, as a function of time (up to 2013). The cumulative amount is shown and each curve is scaled with the total number of papers, which is indicated between brackets. Details on the exact search queries used to generate these statistics are given in Appendix 1.

Figure 5. Convective mass transfer coefficient (CMTC $\left[\mathrm{s} \mathrm{m}^{-1}\right]$ ) on the surface of a wet porous flat plate (mineral plaster) during convective drying, obtained by means of conjugate modelling, from [46]. The CMTC is presented as a function of time (scaled with total time $t_{\text {tot }}$ ) and location on the surface (scaled with the length of the plate $L$ ) calculated from conjugate modelling. The constant drying rate period (CDRP) and decreasing drying rate period (DDRP) are indicated.

Figure 6. Different approaches for modelling both deformation and water transport during dehydration of porous materials ( $X$ : moisture content; $t$ : time; $V$ : volume; $\varepsilon$ : total strain; $\varepsilon_{m}$ : mechanical strain (e.g. elastic); $\varepsilon_{s}$ : shrinkage strain; PDE: partial differential equation; exp.: experimental).

Figure 7. Drying rate as a function of time for convective drying of a wet ceramic brick from [207]. The results of a Monte-Carlo simulation of the drying process are shown, where the heat and moisture transport (material) properties were used as a stochastic input. The resulting statistics of the drying rate (mean, median, minimal, maximal values and $5 \%$ and $95 \%$ quantiles), caused by material property variability, are shown. The drying rate is scaled with the drying rate during the CDRP and the time is scaled with total drying time.

Figure 8. The product-energy-water-process nexus related to drying processes. 
Defraeye T., Advanced computational modelling for drying processes - a review, Applied Energy 131, 323-344.

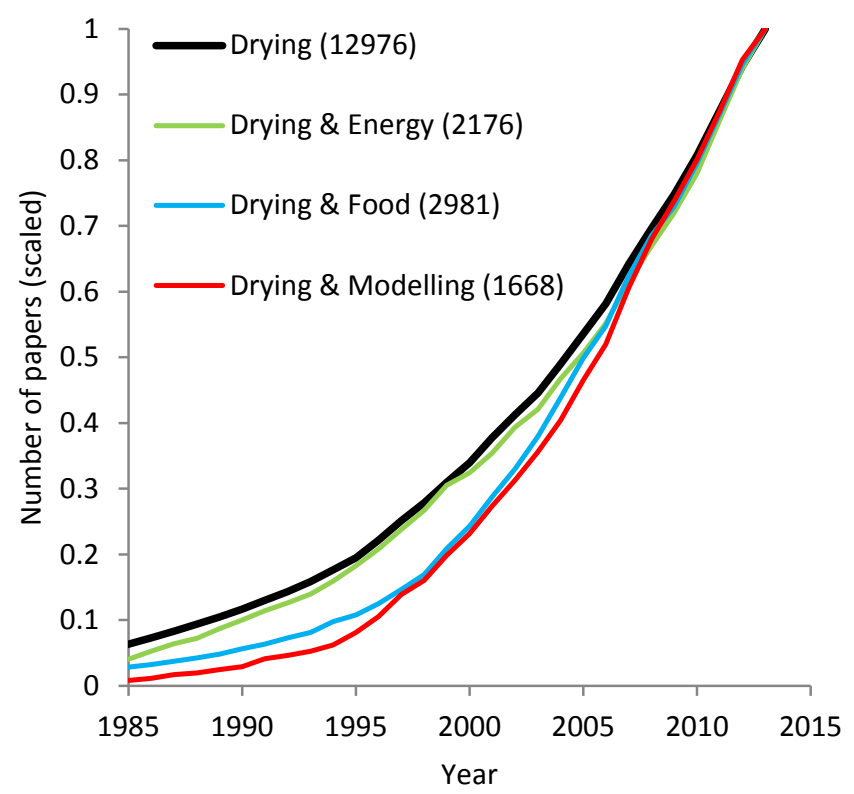

Figure 1. Number of papers on drying technology and its relation to energy, food and modelling, obtained from Scopus for selected journals, as a function of time (up to 2013). The cumulative amount is shown and each curve is scaled with the total number of papers, which is indicated between brackets. Details on the exact search queries used to generate these statistics are given in Appendix 1. 

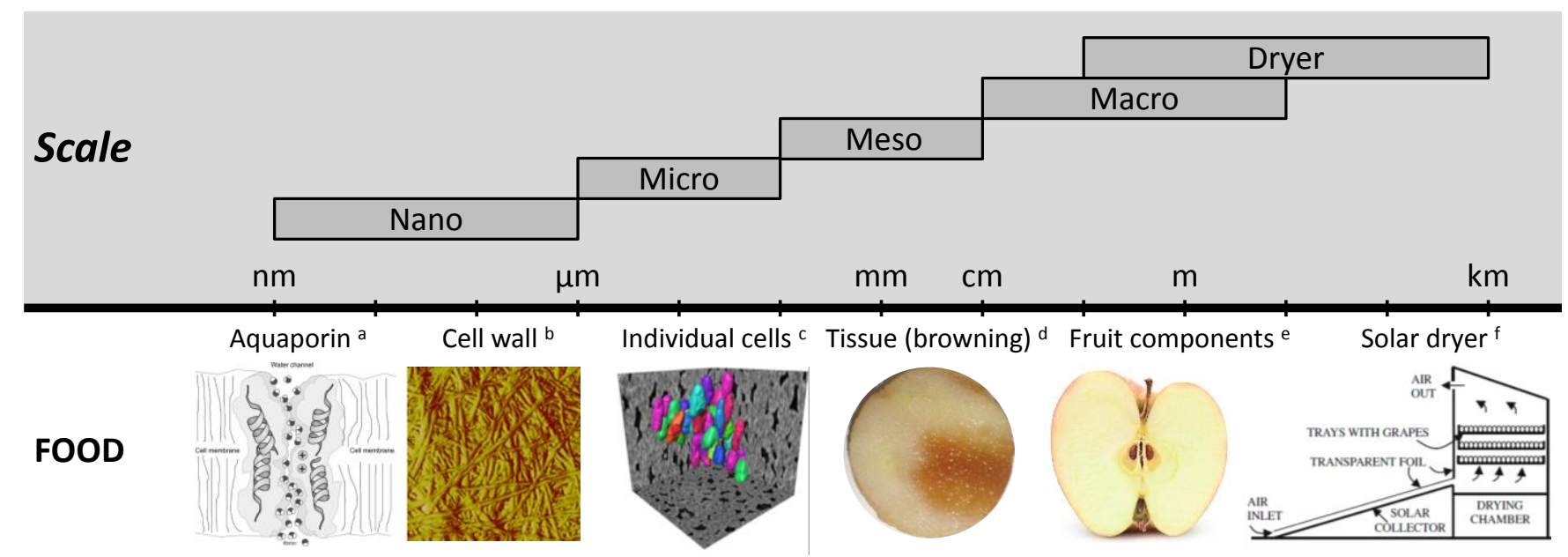

Components: peel, tissue, pit, seed, ... - Constituents: vascular bundle, cortex tissue, lenticel, ...
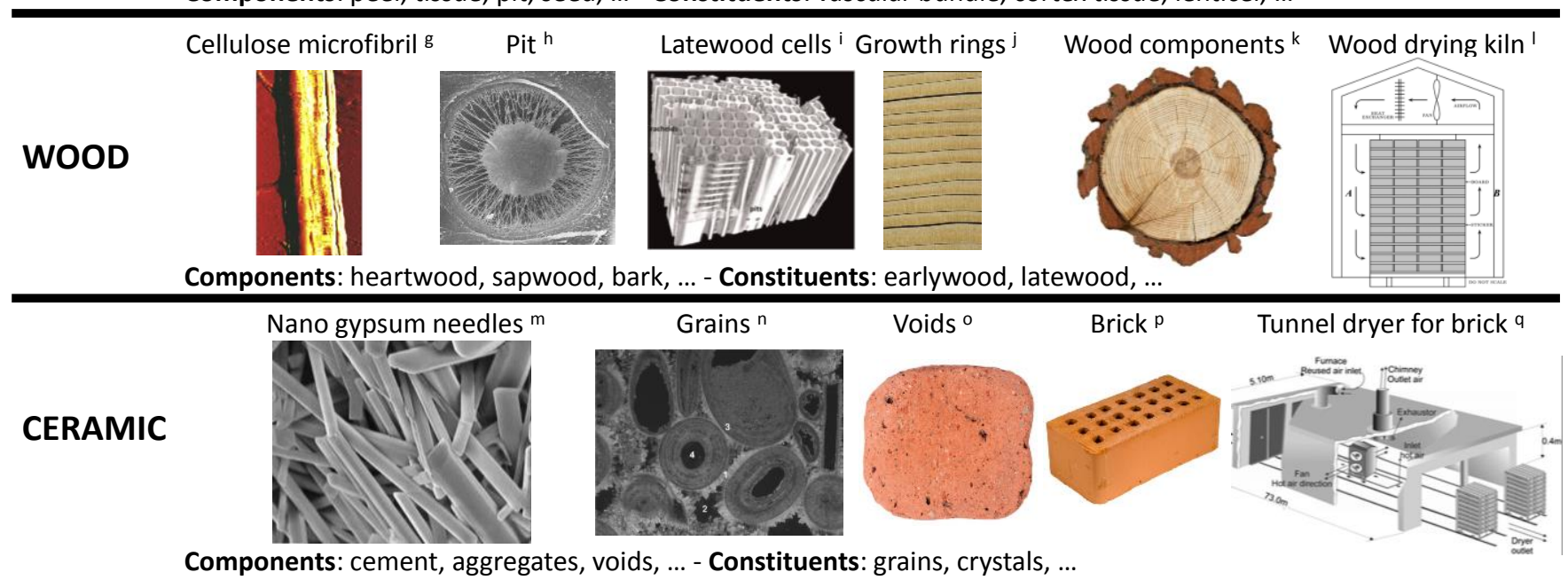

\begin{tabular}{|c|c|c|c|c|c|c|}
\hline Length & $\mathrm{nm}$ & $\mu \mathrm{m}$ & $\mathrm{mm}$ & $\mathrm{cm}$ & $m$ & $\mathrm{~km}$ \\
\hline Time & ns & $\mu \mathrm{s}$ & & $s$ & & \\
\hline
\end{tabular}

Figures taken or adapted from (with permission): (a) [287], (b) [288], (c) [289], (d) [290], (e) OSedneva/Dreamstime.com, (f) [245], (g) [291], (h) [292], (i) [293], (j) [294], (k) Cloanniss/Dreamstime.com, (I) [295], (m) [296], (n) [236], (o) OSarah2/Dreamstime.com, (p)

CAleksandrl/Dreamstime.com, (q) [297]

Figure 2. Multiscale nature of some products relevant to the drying industry. 
Defraeye T., Advanced computational modelling for drying processes - a review, Applied Energy 131, 323-344. http://dx.doi.org/10.1016/j.apenergy.2014.06.027

\section{EXCHANGE PROCESSES}

Heat

- Convection

- Radiation (infrared \& solar)

- Phase change (latent heat of evaporation) - Capillary action

- Conduction (in contact with solid)

\section{Liquid water}

- Phase change (evaporation)

- Diffusion (e.g. osmotic dehydration)
Water vapour \& Air

- Convection

Solid

- Contact forces

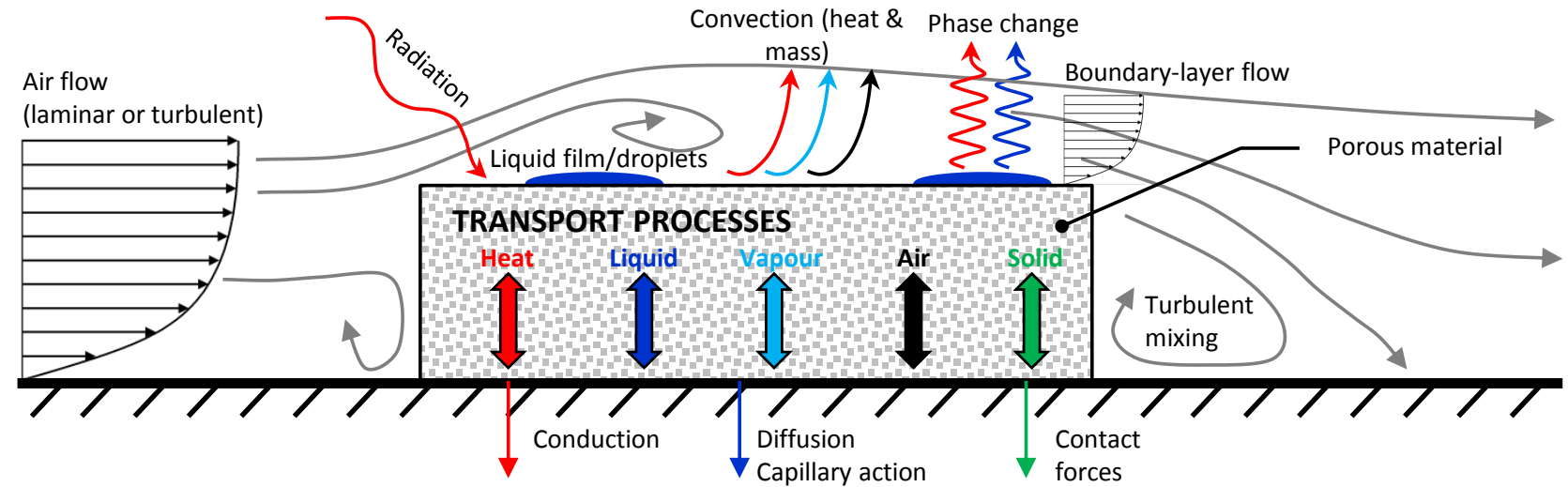

\section{TRANSPORT PROCESSES}

\begin{tabular}{|c|c|c|c|c|c|}
\hline $\begin{array}{l}\text { Transported } \\
\text { variable }\end{array}$ & Heat & $\frac{\text { Mass }}{\text { Liquid }}$ & $\frac{\text { Mass }}{\text { Water vapour }}$ & $\frac{\text { Mass }}{\text { Air }}$ & $\begin{array}{l}\text { Mass } \\
\text { Solid }\end{array}$ \\
\hline $\begin{array}{l}\text { Transport } \\
\text { mechanisms }\end{array}$ & $\begin{array}{l}\text { - Diffusion (Fourier, mass diffusion, } \\
\text { Dufour effect) } \\
\text { - Advection (mass convection) }\end{array}$ & $\begin{array}{l}\text { - Diffusion (osmosis, surface } \\
\text { diffusion, thermally driven) } \\
\text { - Convection (Darcy) }\end{array}$ & $\begin{array}{l}\text { - Diffusion (Fick, Knudsen } \\
\text { diffusion, Soret effect) } \\
\text { - Convection (Darcy) }\end{array}$ & $\begin{array}{l}\text { - Diffusion (Fick, } \\
\text { Knudsen diffusion, } \\
\text { Soret effect) } \\
\text { - Convection (Darcy) }\end{array}$ & $\begin{array}{l}\text { - Mechanical } \\
\text { deformation }^{\text {a }}\end{array}$ \\
\hline $\begin{array}{l}\text { Volumetric } \\
\text { sources/sinks }\end{array}$ & $\begin{array}{l}\text { - Phase change (latent heat of } \\
\text { evaporation \& heat of desorption) } \\
\text { - Electromagnetic radiation (e.g. } \\
\text { microwave) } \\
\text { - Chemical binding/release energy (e.g. } \\
\text { water in gypsum) }\end{array}$ & $\begin{array}{l}\text { - Phase change (evaporation \& } \\
\text { desorption) } \\
\text { - Chemical binding/release of water } \\
\text { - Gravity }\end{array}$ & $\begin{array}{l}\text { - Phase change } \\
\text { (evaporation \& } \\
\text { desorption) }\end{array}$ & - None & - Gravity \\
\hline Driving forces & $\begin{array}{l}\text { - Temperature } \\
\text { - Concentration (of gas) }\end{array}$ & $\begin{array}{l}\text { - Capillary pressure (surface tension) } \\
\text { - Gas/liquid pressure } \\
\text { - Concentration (of solutes) } \\
\text { - Temperature }\end{array}$ & $\begin{array}{l}\text { - Gas pressure } \\
\text { - Concentration (of } \\
\text { vapour) } \\
\text { - Temperature }\end{array}$ & $\begin{array}{l}\text { - Gas pressure } \\
\text { - Concentration (of } \\
\text { dry air) } \\
\text { - Temperature }\end{array}$ & $\begin{array}{l}\text { - Water content } \\
\text { - Temperature }\end{array}$ \\
\hline
\end{tabular}

Figure 3. Transport processes inside porous materials as well as exchange processes at air-material (or materialmaterial) interfaces. The focus is on processes most relevant to drying. 
Defraeye T., Advanced computational modelling for drying processes - a review, Applied Energy 131, 323-344. http://dx.doi.org/10.1016/j.apenergy.2014.06.027

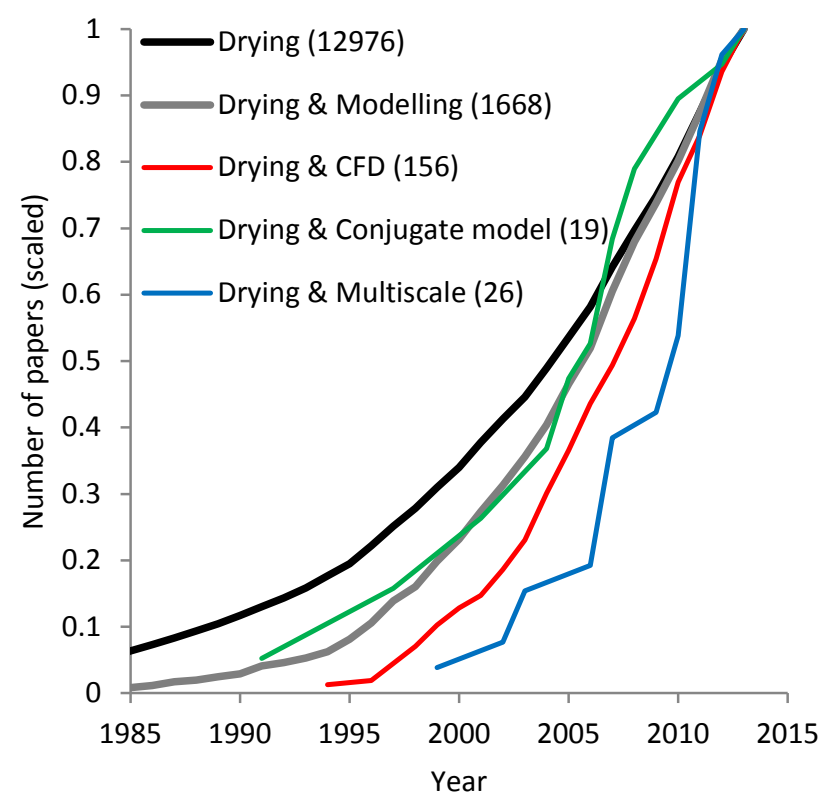

Figure 4. Number of papers on drying technology and its relation to some advanced computational methods, obtained from Scopus for selected journals, as a function of time (up to 2013). The cumulative amount is shown and each curve is scaled with the total number of papers, which is indicated between brackets. Details on the exact search queries used to generate these statistics are given in Appendix 1. 
Defraeye T., Advanced computational modelling for drying processes - a review, Applied Energy 131, 323-344.

http://dx.doi.org/10.1016/j.apenergy.2014.06.027

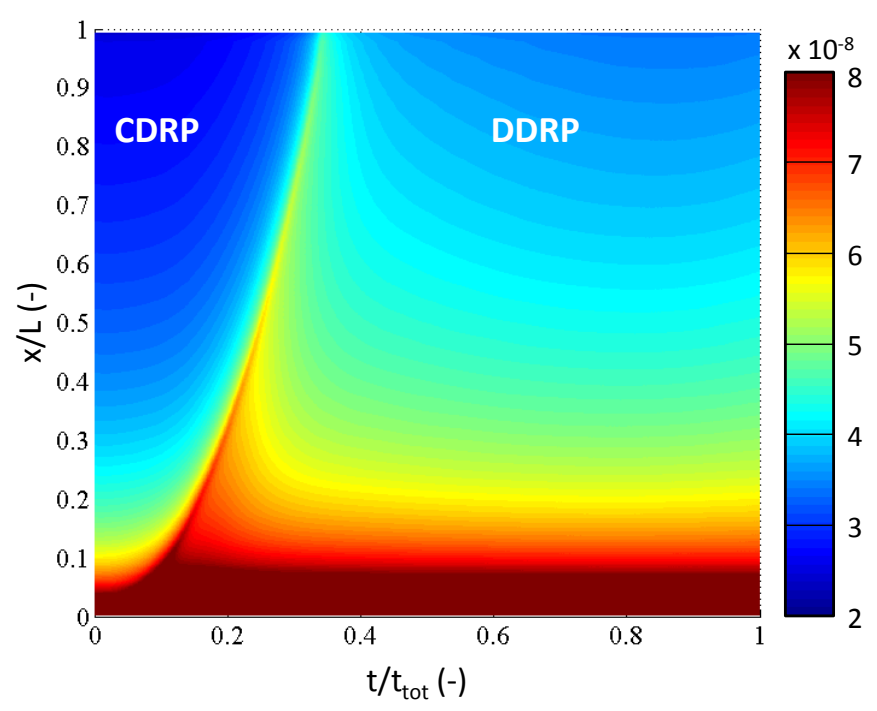

Figure 5. Convective mass transfer coefficient (CMTC $\left[\mathrm{s} \mathrm{m}^{-1}\right]$ ) on the surface of a wet porous flat plate (mineral plaster) during convective drying, obtained by means of conjugate modelling, from [46]. The CMTC is presented as a function of time (scaled with total time $t_{\text {tot }}$ ) and location on the surface (scaled with the length of the plate $L$ ) calculated from conjugate modelling. The constant drying rate period (CDRP) and decreasing drying rate period (DDRP) are indicated. 
Defraeye T., Advanced computational modelling for drying processes - a review, Applied Energy 131, 323-344. http://dx.doi.org/10.1016/j.apenergy.2014.06.027
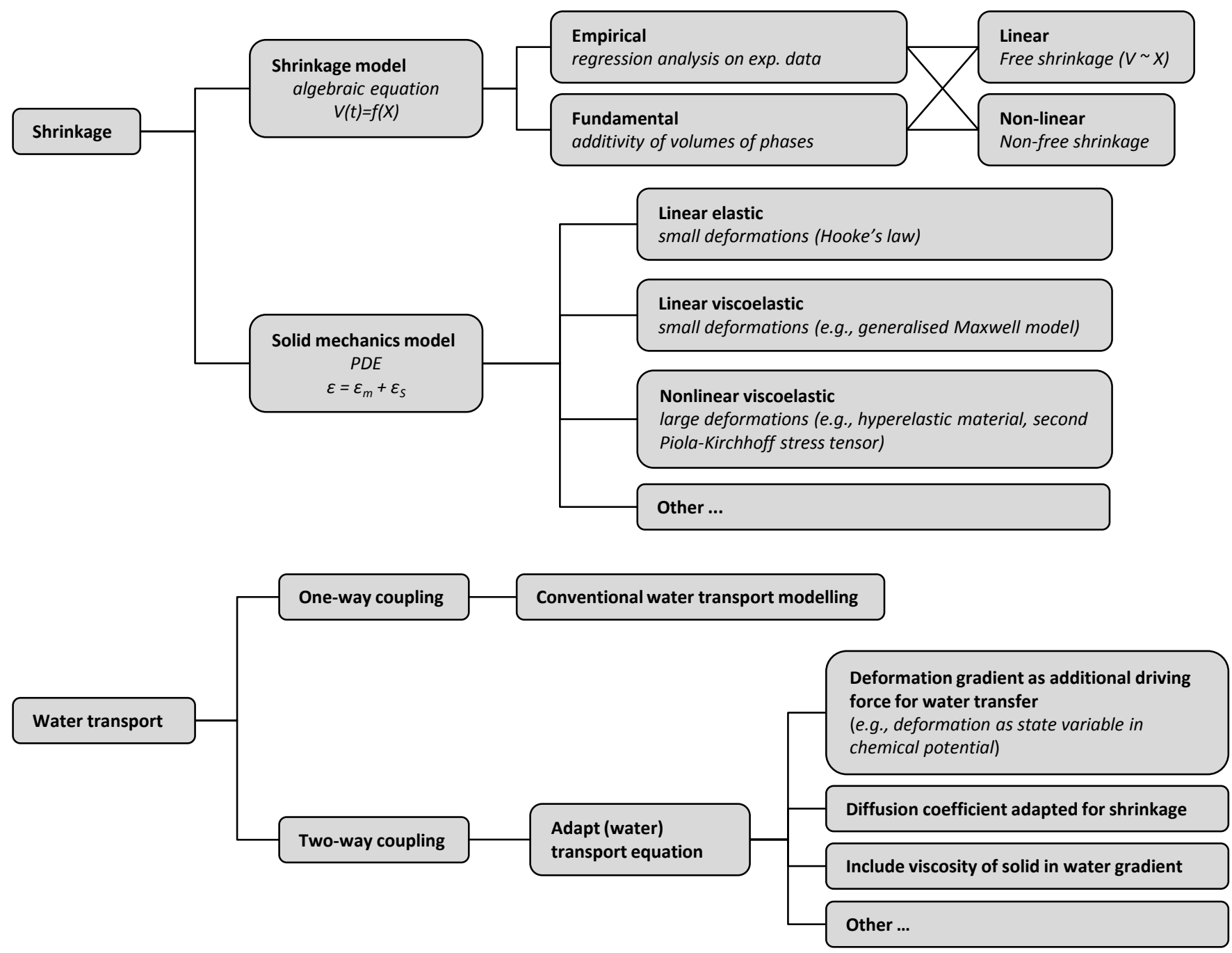

Figure 6. Different approaches for modelling both deformation and water transport during dehydration of porous materials ( $X$ : moisture content; $t$ : time; $V$ : volume; $\varepsilon$ : total strain; $\varepsilon_{m}$ : mechanical strain (e.g. elastic); $\varepsilon_{s}$ : shrinkage strain; PDE: partial differential equation; exp.: experimental). 
Defraeye T., Advanced computational modelling for drying processes - a review, Applied Energy 131, 323-344.

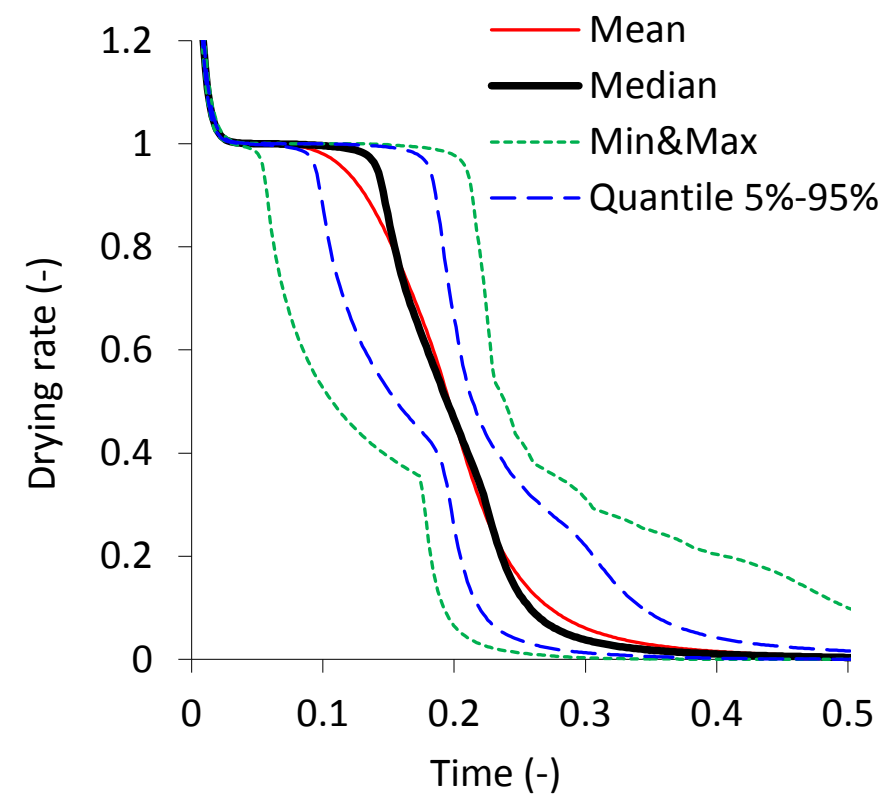

Figure 7. Drying rate as a function of time for convective drying of a wet ceramic brick from [207]. The results of a Monte-Carlo simulation of the drying process are shown, where the heat and moisture transport (material) properties were used as a stochastic input. The resulting statistics of the drying rate (mean, median, minimal, maximal values and $5 \%$ and $95 \%$ quantiles), caused by material property variability, are shown. The drying rate is scaled with the drying rate during the CDRP and the time is scaled with total drying time. 
Defraeye T., Advanced computational modelling for drying processes - a review, Applied Energy 131, 323-344.

http://dx.doi.org/10.1016/j.apenergy.2014.06.027

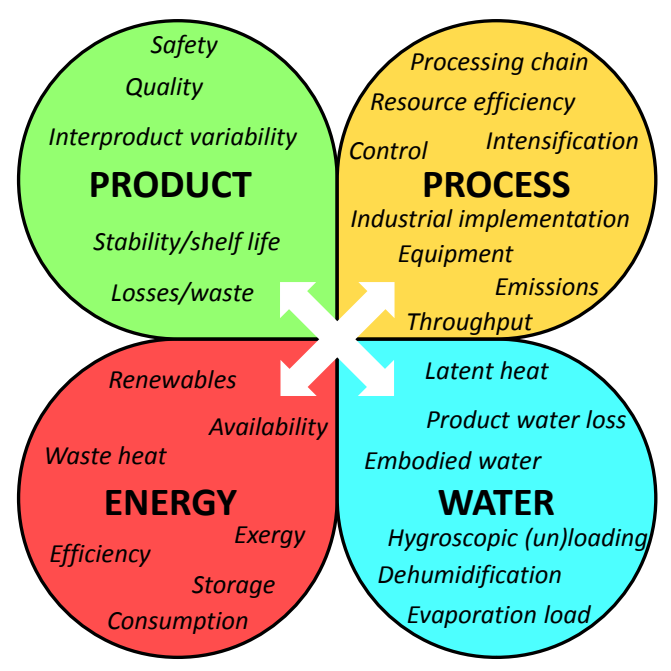

Figure 8. The product-energy-water-process nexus related to drying processes. 


\section{References}

[1] Mujumdar AS. Handbook of Industrial Drying. Third edit. CRC Press, Taylor \& Francis Group, Boca Raton, USA; 2006.

[2] Kudra T. Energy aspects in drying. Dry Technol 2004;22:917-32.

[3] Kemp IC. Fundamentals of Energy Analysis of Dryers. In: Tsotsas E, Mujumdar AS, editors. Mod. Dry. Technol. - Energy Savings, Weinheim: Wiley-VCH Verlag GmbH; 2011, p. 1-46.

[4] Kerkhof PJAM, Coumans WJ. Drying: a fascinating unit operation. Chem Eng J 2002;86:1-2.

[5] IEA. International Energy Agency - World Energy Outlook fact sheet (http://www.worldenergyoutlook.org/resources/factsheets/) 2011.

[6] Mujumdar AS, Huang L-X. Global R\&D needs in drying. Dry Technol 2007;25:647-58.

[7] Chou SK, Chua KJ. New hybrid drying technologies for heat sensitive foodstuffs. Trends Food Sci Technol 2001;12:359-69.

[8] Zhang M, Tang J, Mujumdar a. S, Wang S. Trends in microwave-related drying of fruits and vegetables. Trends Food Sci Technol 2006;17:524-34.

[9] Krishnamurthy K, Khurana HK, Jun S, Irudayaraj J, Demirci A. Infrared heating in food processing: An overview. Compr Rev Food Sci Food Saf 2008;7:2-13.

[10] Kudra T, Mujumdar AS. Advanced Drying Technologies. Second edi. CRC Press, Taylor \& Francis Group, Boca Raton, USA; 2009.

[11] Dev SRS, Raghavan VGS. Advancements in drying techniques for food, fiber, and fuel. Dry Technol 2012;30:1147-59.

[12] Jangam SV. An overview of recent developments and some R\&D challenges related to drying of foods. Dry Technol 2011;29:1343-57.

[13] Mujumdar AS. Research and development in drying: Recent trends and future prospects. Dry Technol 2004;22:1-26.

[14] Mujumdar AS. An overview of innovation in industrial drying: current status and R\&D needs. Transp Porous Media 2006;66:3-18.

[15] Kemp IC. Process-systems Simulation Tools. In: Tsotsas E, Mujumdar AS, editors. Mod. Dry. Technol. - Comput. Tools Differ. Scales, vol. 1, Weinheim, Germany: Wiley-VHC Verlag GmbH; 2007, p. 261-305. 
[16] Banga JR, Balsa-Canto E, Alonso AA. Quality and safety models and optimization as part of computer-integrated manufacturing. Compr Rev Food Sci Food Saf 2008;7:168-74.

[17] Menshutina N V., Kudra T. Computer aided drying technologies. Dry Technol 2001;19:1825-49.

[18] Wang HG, Yang WQ, Senior P, Raghavan RS, Duncan SR. Investigation of batch fluidized-bed drying by mathematical modeling, CFD simulation and ECT measurement. AIChE J 2008;54:42744.

[19] Datta AK. Porous media approaches to studying simultaneous heat and mass transfer in food processes. II: Property data and representative results. J Food Eng 2007;80:96-110.

[20] Datta AK. Porous media approaches to studying simultaneous heat and mass transfer in food processes. I: Problem formulations. J Food Eng 2007;80:80-95.

[21] Stawreberg L, Nilsson L. Potential energy savings made by using a specific control strategy when tumble drying small loads. Appl Energy 2013;102:484-91.

[22] Song H, Starfelt F, Daianova L, Yan J. Influence of drying process on the biomass-based polygeneration system of bioethanol, power and heat. Appl Energy 2012;90:32-7.

[23] Yadav V, Moon CG. Fabric-drying process in domestic dryers. Appl Energy 2008;85:143-58.

[24] Yadav V, Moon CG. Modelling and experimentation for the fabric-drying process in domestic dryers. Appl Energy 2008;85:404-19.

[25] Ng AB, Deng S. A new termination control method for a clothes drying process in a clothes dryer. Appl Energy 2008;85:818-29.

[26] Gong Z-X, Mujumdar AS. Software for Design and Analysis of Drying Systems. Dry Technol 2008;26:884-94.

[27] Kemp IC. Drying Software: Past, Present, and Future. Dry Technol 2007;25:1249-63.

[28] Datta AK. Status of physics-based models in the design of food products, processes, and equipment. Compr Rev Food Sci Food Saf 2008;7:121-9.

[29] Gulati T, Datta AK. Enabling computer-aided food process engineering: Property estimation equations for transport phenomena-based models. J Food Eng 2013;116:483-504.

[30] Strumillo C. Perspectives on developments in drying. Dry Technol 2006;24:1059-68.

[31] Mujumdar AS, Zhonghua W. Thermal drying technologies - cost-effective innovation aided by mathematical modeling approach. Dry Technol 2007;26:145-53. 
[32] Chua KJ, Chou SK. Low-cost drying methods for developing countries. Trends Food Sci Technol 2003;14:519-28.

[33] Garau MC, Simal S, Femenia A, Rosselló C. Drying of orange skin: drying kinetics modelling and functional properties. J Food Eng 2006;75:288-95.

[34] Oliviero T, Verkerk R, Dekker M. A research approach for quality based design of healthy foods: Dried broccoli as a case study. Trends Food Sci Technol 2013;30:178-84.

[35] Palzer S, Dubois C, Gianfrancesco A. Generation of product structures during drying of food products. Dry Technol 2012;30:97-105.

[36] Betoret E, Betoret N, Vidal D, Fito P. Functional foods development: Trends and technologies. Trends Food Sci Technol 2011;22:498-508.

[37] Van der Sman RGM, van der Goot AJ. The science of food structuring. Soft Matter 2009;5:50110.

[38] FAO. "Energy-smart" food for people and climate - Issue paper (www.fao.org). Rome, Italy: 2011.

[39] Masanet E, Worrell E, Graus W, Galitsky C. Energy efficiency improvement and cost saving opportunities for the fruit and vegetable processing industry - An ENERGY STAR Guide for Energy and Plant Managers. 2008.

[40] Mujumdar AS. Some recent developments in drying technologies appropriate for postharvest processing. Int J Postharvest Technol Innov 2006;1:76-92.

[41] Dufour P. Control engineering in drying technology: review and trends. Dry Technol 2006;24:889904.

[42] Chen XD, Mujumdar AS. Drying Technologies in Food Processing. First edit. Wiley-Blackwell; 2008.

[43] Tsotsas E, Mujumdar AS. Modern Drying Technology - Volume 1 - Computational Tools at Different Scales. Wiley-VHC Verlag GmbH, Weinheim, Germany; 2007.

[44] Turner IW, Mujumdar AS. Mathematical Modeling and Numerical Techniques in Drying Technology. First. New York: Marcel Dekker Inc.; 1996.

[45] Dhall A, Datta AK. Transport in deformable food materials: A poromechanics approach. Chem Eng Sci 2011;66:6482-97.

[46] Defraeye T, Blocken B, Carmeliet J. Analysis of convective heat and mass transfer coefficients for convective drying of a porous flat plate by conjugate modelling. Int J Heat Mass Transf 2012;55:112-24. 
[47] Halder A, Dhall A, Datta AK. Modeling transport in porous media with phase change: applications to food processing. J Heat Transfer 2011;133:031010-1-13.

[48] Mcminn WAM, Magee TRA. Principles, methods and applications of the convective drying of foodstuffs. Food Bioprod Process 1999;77:175-93.

[49] Carmeliet J, Descamps F, Houvenaghel G. A multiscale network model for simulating moisture transfer properties of porous media. Transp Porous Media 1999;35:67-88.

[50] Metzger T, Tsotsas E, Prat M. Pore-network models : A powerful tool to study drying at the pore level and understand the influence of structure on drying kinetics. In: Tsotsas E, Mujumdar AS, editors. Mod. Dry. Technol. - Vol. 1 - Comput. Tools Differ. Scales, Wiley-VHC Verlag GmbH, Weinheim, Germany; 2007, p. 57-102.

[51] Prat M. On the influence of pore shape, contact angle and film flows on drying of capillary porous media. Int J Heat Mass Transf 2007;50:1455-68.

[52] Vorhauer N, Tran QT, Metzger T, Tsotsas E, Prat M. Experimental investigation of drying in a model porous medium: influence of thermal gradients. Dry Technol 2013;31:920-9.

[53] Holbrook MN, Zwieniecki MA. Vascular Transport in Plants. First edit. London: Elsevier Academic Press; 2005.

[54] Domec J-C, Lachenbruch B, Meinzer FC. Bordered pit structure and function determine spatial patterns of air-seeding thresholds in xylem of Douglas-fir (Pseudotsuga menziesii; Pinaceae) trees. Am J Bot 2006;93:1588-600.

[55] Bonazzi C, Dumoulin E. Quality changes in food materials as influenced by drying processes. In: Tsotsas E, Mujumdar AS, editors. Mod. Dry. Technol. - Prod. Qual. Formul., vol. 3, Wiley-VHC Verlag GmbH, Weinheim, Germany; 2011, p. 1-20.

[56] Hwang C-C, Lin C-M, Kung H-F, Huang Y-L, Hwang D-F, Su Y-C, et al. Effect of salt concentrations and drying methods on the quality and formation of histamine in dried milkfish (Chanos chanos). Food Chem 2012;135:839-44.

[57] Fang S, Wang Z, Hu X, Datta AK. Hot-air drying of whole fruit Chinese jujube (Zizyphus jujuba Miller): physicochemical properties of dried products. Int J Food Sci Technol 2009;44:1415-21.

[58] Frank X, Perré P. The potential of meshless methods to address physical and mechanical phenomena involved during drying at the pore level. Dry Technol 2010;28:932-43.

[59] Perré P. Multiscale modeling of drying as a powerful extension of the macroscopic approach: application to solid wood and biomass processing. Dry Technol 2010;28:944-59.

[60] Katekawa ME, Silva MA. A review of drying models including shrinkage effects. Dry Technol 2006;24:5-20. 
[61] Philip JR, De Vries DA. Moisture movement in porous materials under temperature gradients. Trans Am Geophys Union 1957;38:222-32.

[62] Luikov AV. Heat and mass transfer in capillary-porous bodies. First edit. New York: Pergamon Press; 1966.

[63] Luikov AV. Application of the methods of thermodynamics of irreversible processes to the investigation of heat and mass transfer. J Eng Phys 1965;9:189-202.

[64] Bowen RM. Incompressible porous media models by use of the theory of mixtures. Int J Eng Sci 1980;18:1129-48.

[65] Bowen RM. Compressible porous media models by use of the theory of mixtures. Int J Eng Sci 1982;20:697-735.

[66] Kowalski SJ. Toward a thermodynamics and mechanics of drying processes. Chem Eng Sci 2000;55:1289-304.

[67] Kowalski SJ. Continuous Thermohydromechanical Model using the Theory of Mixtures. In: Tsotsas E, Mujumdar AS, editors. Mod. Dry. Technol. - Vol 1 - Comput. Tools Differ. Scales, Wiley-VHC Verlag GmbH, Weinheim, Germany; 2007, p. 125-54.

[68] Whitaker S. Coupled transport in multiphase systems: A theory of drying. Adv Heat Transf 1998;31:1-104.

[69] Whitaker S. Simultaneous heat, mass, and momentum transfer in porous media: A theory of drying. Adv Heat Transf 1977;13:119-203.

[70] Perré P, Rémond R, Turner IW. Comprehensive drying models based on volume averaging : background, application and perspective. In: Tsotsas E, Mujumdar AS, editors. Mod. Dry. Technol. - Vol 1 - Comput. Tools Differ. Scales, vol. V, Wiley-VHC Verlag GmbH, Weinheim, Germany; 2007, p. 1-55.

[71] Couture F, Bernada P, Roques MA. Continuous Thermomechanical Models using VolumeAveraging Theory. In: Tsotsas E, Mujumdar AS, editors. Mod. Dry. Technol. - Vol 1 - Comput. Tools Differ. Scales, Wiley-VHC Verlag GmbH, Weinheim, Germany; 2007, p. 103-24.

[72] Farid M. The moving boundary problems from melting and freezing to drying and frying of food. Chem Eng Process 2002;41:1-10.

[73] Hashimoto A, Stenström S, Kameoka T. Simulation of convective drying of wet porous materials. Dry Technol 2003;21:1411-31.

[74] Wang L, Sun D-W. Recent developments in numerical modelling of heating and cooling processes in the food industry - a review. Trends Food Sci Technol 2003;14:408-23. 
[75] Defraeye T, Blocken B, Derome D, Nicolai B, Carmeliet J. Convective heat and mass transfer modelling at air-porous material interfaces: Overview of existing methods and relevance. Chem Eng Sci 2012;74:49-58.

[76] Gad-el-Hak M. The fluid mechanics of microdevices — The Freeman scholar lecture. J Fluids Eng 1999;121:5-33.

[77] Gad-el-Hak M. Differences between liquid and gas transport at the microscale. Bull Polisch Acad Sci 2005;53:301-16.

[78] Gad-el-Hak M. Gas and liquid transport at the microscale. Heat Transf Eng 2006;27:13-29.

[79] Van Marcke P, Verleye B, Carmeliet J, Roose D, Swennen R. An improved pore network model for the computation of the saturated permeability of porous rock. Transp Porous Media 2010;85:451-76.

[80] Prat M. Recent advances in pore-scale models for drying of porous media. Chem Eng J 2002;86:153-64.

[81] Prat M. Percolation model of drying under isothermal conditions in porous media. Int J Multiph Flow 1993;19:691-704.

[82] Yiotis AG, Tsimpanogiannis IN, Stubos AK, Yortsos YC. Pore-network study of the characteristic periods in the drying of porous materials. J Colloid Interface Sci 2006;297:738-48.

[83] Huinink HP, Pel L, Michels MAJ, Prat M. Drying processes in the presence of temperature gradients - pore-scale modelling. Eur Phys J E Soft Matter 2002;9:487-98.

[84] Surasani VK, Metzger T, Tsotsas E. Consideration of heat transfer in pore network modelling of convective drying. Int J Heat Mass Transf 2008;51:2506-18.

[85] Segura LA, Toledo PG. Pore-level modeling of isothermal drying of pore networks. Chem Eng J 2005;111:237-52.

[86] Frank X, Almeida G, Perré P. Multiphase flow in the vascular system of wood: From microscopic exploration to 3-D Lattice Boltzmann experiments. Int J Multiph Flow 2010;36:599-607.

[87] Schulte PJ. Computational fluid dynamics models of conifer bordered pits show how pit structure affects flow. New Phytol 2012;193:721-9.

[88] Haile JM. Molecular Dynamics Simulation: Elementary Methods. First edit. New York: Wiley Interscience; 1997.

[89] Kulasinski K, Keten S, Churakov S V., Derome D, Carmeliet J. A comparative molecular dynamics study of crystalline, paracrystalline and amorphous states of cellulose. Cellulose 2014:DOI 10.1007/s10570-014-0213-7. 
[90] Lewicki PP. Design of hot air drying for better foods. Trends Food Sci Technol 2006;17:153-63.

[91] Voda A, Homan N, Witek M, Duijster A, van Dalen G, van der Sman RGM, et al. The impact of freeze-drying on microstructure and rehydration properties of carrot. Food Res Int 2012;49:68793.

[92] Lewicki PP, Pawlak G. Effect of drying on microstructure of plant tissue. Dry Technol 2003;21:657-83.

[93] Perré P. A review of modern computational and experimental tools relevant to the field of drying. Dry Technol 2011;29:1529-41.

[94] Jamaleddine TJ, Ray MB. Application of computational fluid dynamics for simulation of drying processes: A review. Dry Technol 2010;28:120-54.

[95] Kuriakose R, Anandharamakrishnan C. Computational fluid dynamics (CFD) applications in spray drying of food products. Trends Food Sci Technol 2010;21:383-98.

[96] Langrish TAG, Fletcher DF. Spray drying of food ingredients and applications of CFD in spray drying 2001;40:345-54.

[97] Mujumdar AS, Huang L-X, Chen XD. An overview of the recent advances in spray-drying. Dairy Sci Technol 2010;90:211-24.

[98] Fletcher DF, Guo B, Harvie DJE, Langrish TAG, Nijdam JJ, Williams J. What is important in the simulation of spray dryer performance and how do current CFD models perform? Appl Math Model 2006;30:1281-92.

[99] Xia B, Sun D-W. Applications of computational fluid dynamics (CFD) in the food industry: a review. Comput Electron Agric 2002;34:5-24.

[100] Norton T, Sun D-W. Computational fluid dynamics (CFD) - an effective and efficient design and analysis tool for the food industry: A review. Trends Food Sci Technol 2006;17:600-20.

[101] Norton T, Tiwari B, Sun D-W. Computational fluid dynamics in the design and analysis of thermal processes: a review of recent advances. Crit Rev Food Sci Nutr 2013;53:251-75.

[102] Kurnia JC, Sasmito AP, Tong W, Mujumdar AS. Energy-efficient thermal drying using impingingjets with time-varying heat input - A computational study. J Food Eng 2013;114:269-77.

[103] Yadav AS, Bhagoria JL. Heat transfer and fluid flow analysis of solar air heater: A review of CFD approach. Renew Sustain Energy Rev 2013;23:60-79.

[104] Barresi AA, Pisano R, Rasetto V, Fissore D, Marchisio DL. Model-based monitoring and control of industrial freeze-drying processes: effect of batch nonuniformity. Dry Technol 2010;28:577-90. 
[105] Smolka J, Nowak AJ, Rybarz D. Improved 3-D temperature uniformity in a laboratory drying oven based on experimentally validated CFD computations. J Food Eng 2010;97:373-83.

[106] Böhner M, Barfuss I, Heindl A, Müller J. Improving the airflow distribution in a multi-belt conveyor dryer for spice plants by modifications based on computational fluid dynamics. Biosyst Eng 2013;115:339-45.

[107] Shokouhmand H, Abdollahi V, Hosseini S, Vahidkhah K. Performance optimization of a brick dryer using porous simulation approach. Dry Technol 2011;29:360-70.

[108] Ducept F, Sionneau M, Vasseur J. Superheated steam dryer : simulations and experiments on product drying. Chem Eng J 2002;86:75-83.

[109] Casey M, Wintergerste T. ERCOFTAC Special Interest Group on "Quality and Trust in Industrial CFD” - Best Practice Guidelines. First edit. ERCOFTAC; 2000.

[110] Fletcher DF, Langrish TAG. Scale-adaptive simulation (SAS) modelling of a pilot-scale spray dryer. Chem Eng Res Des 2009;87:1371-8.

[111] Harvie DJE, Langrish TAG, Fletcher DF. Numerical simulations of gas flow patterns within a tallform spray dryer. Chem Eng Res Des 2001;79.

[112] Jongsma FJ, Innings F, Olsson M, Carlsson F. Large eddy simulation of unsteady turbulent flow in a semi-industrial size spray dryer. Dairy Sci Technol 2013;93:373-86.

[113] Chilton TH, Colburn AP. Mass transfer (absorption) coefficients. Ind Eng Chem 1934;26:1183-7.

[114] Verboven P, Nicolai B, Scheerlinck N, De Baerdemaeker J. The local surface heat transfer coefficient in thermal food process calculations : A CFD approach. J Food Eng 1997;33:15-35.

[115] Kondjoyan A. A review on surface heat and mass transfer coefficients during air chilling and storage of food products. Int J Refrig 2006;29:863-75.

[116] Kaya A, Aydin O, Dincer I. Numerical modeling of heat and mass transfer during forced convection drying of rectangular moist objects. Int J Heat Mass Transf 2006;49:3094-103.

[117] Chandra Mohan VP, Talukdar P. Three dimensional numerical modeling of simultaneous heat and moisture transfer in a moist object subjected to convective drying. Int J Heat Mass Transf 2010;53:4638-50.

[118] Kondjoyan A, Boisson HC. Comparison of calculated and experimental heat transfer coefficients at the surface of circular cylinders placed in a turbulent cross-flow of air. J Food Eng 1997;34:12343. 
[119] Defraeye T, Herremans E, Verboven P, Carmeliet J, Nicolai B. Convective heat and mass exchange at surfaces of horticultural products: A microscale CFD modelling approach. Agric For Meteorol 2012;162-163:71-84.

[120] Tremblay C, Cloutier A, Fortin Y. Experimental determination of the convective heat and mass transfer coefficients for wood drying. Wood Sci Technol 2000;34:253-76.

[121] Defraeye T, Verboven P, Derome D, Carmeliet J, Nicolai B. Stomatal transpiration and droplet evaporation on leaf surfaces by a microscale modelling approach. Int J Heat Mass Transf 2013;65:180-91.

[122] Halder A, Datta AK. Surface heat and mass transfer coefficients for multiphase porous media transport models with rapid evaporation. Food Bioprod Process 2012;90:475-90.

[123] Moraga NO, Medina EE. Conjugate forced convection and heat conduction with freezing of water content in a plate shaped food. Int J Heat Mass Transf 2000;43:53-67.

[124] Defraeye T, Blocken B, Carmeliet J. CFD analysis of convective heat transfer at the surfaces of a cube immersed in a turbulent boundary layer. Int J Heat Mass Transf 2010;53:297-308.

[125] Lienhard JH (IV), Lienhard JH (V). A Heat Transfer Textbook. Third edit. Cambridge Massachusetts: Phlogiston Press; 2006.

[126] Defraeye T, Verboven P, Nicolai B. CFD modelling of flow and scalar exchange of spherical food products: Turbulence and boundary-layer modelling. J Food Eng 2013;114:495-504.

[127] Launder BE. On the computation of convective heat transfer in complex turbulent flows. Trans ASME J Heat Transf 1988;110:1112-28.

[128] Murakami S. Comparison of various turbulence models applied to a bluff body. J Wind Eng Ind Aerodyn 1993;46-47:21-36.

[129] Ljung A-L, Staffan Lundström T, Daniel Marjavaara B, Tano K. Convective drying of an individual iron ore pellet - Analysis with CFD. Int J Heat Mass Transf 2011;54:3882-90.

[130] Ljung A-L, Lundström TS, Marjavaara BD, Tano K. Influence of air humidity on drying of individual iron ore pellets. Dry Technol 2011;29:1101-11.

[131] Nijdam JJ, Guo B, Fletcher DF, Langrish TAG. Challenges of simulating droplet coalescence within a spray. Dry Technol 2004;22:1463-88.

[132] Nijdam JJ, Guo B, Fletcher DF, Langrish TAG. Lagrangian and Eulerian models for simulating turbulent dispersion and coalescence of droplets within a spray. Appl Math Model 2006;30:1196211. 
[133] Chiesa M, Mathiesen V, Melheim JA, Halvorsen B. Numerical simulation of particulate flow by the Eulerian-Lagrangian and the Eulerian-Eulerian approach with application to a fluidized bed. Comput Chem Eng 2005;29:291-304.

[134] Sommerfeld M, van Wachen B, Oliemans R. ERCOFTAC Best practice guidelines for Computational Fluid Dynamics of dispersed multiphase flows. ERCOFTAC; 2008.

[135] Zhang Z, Chen Q. Comparison of the Eulerian and Lagrangian methods for predicting particle transport in enclosed spaces. Atmos Environ 2007;41:5236-48.

[136] Mostafa AA, Mongia HC. On the modeling of turbulent evaporating sprays: Eulerian versus Lagrangian approach. Int J Heat Mass Transf 1987;30:2583-93.

[137] Lakehal D. On the modelling of multiphase turbulent flows for environmental and hydrodynamic applications. Int J Multiph Flow 2002;28:823-63.

[138] Langrish TAG. Multi-scale mathematical modelling of spray dryers. J Food Eng 2009;93:218-28.

[139] Mezhericher M, Naumann M, Peglow M, Levy A, Tsotsas E, Borde I. Continuous species transport and population balance models for first drying stage of nanosuspension droplets. Chem Eng $\mathbf{J}$ 2012;210:120-35.

[140] Mortier STFC, De Beer T, Gernaey K V., Remon JP, Vervaet C, Nopens I. Mechanistic modelling of fluidized bed drying processes of wet porous granules: a review. Eur J Pharm Biopharm 2011;79:205-25.

[141] Kumar J, Peglow M, Warnecke G, Heinrich S, Tsotsas E, Hounslow M, et al. Numerical Methods on Population Balances. In: Tsotsas E, Mujumdar AS, editors. Mod. Dry. Technol. - Vol. 1 Comput. Tools Differ. Scales, Wiley-VHC Verlag GmbH, Weinheim, Germany; 2007, p. 209-60.

[142] Chen XD. The basics of a reaction engineering approach to modeling air-drying of small droplets or thin-layer materials. Dry Technol 2008;26:627-39.

[143] Woo MW, Daud WRW, Mujumdar AS, Wu Z, Meor Talib M, Tasirin SM. CFD Evaluation of droplet drying models in a spray dryer fitted with a rotary atomizer. Dry Technol 2008;26:118098.

[144] Putranto A, Dong X, Devahastin S, Xiao Z, Webley PA. Application of the reaction engineering approach (REA) for modeling intermittent drying under time-varying humidity and temperature. Chem Eng Sci 2011;66:2149-56.

[145] Woo MW, Daud WRW, Mujumdar AS, Talib MZM, Hua WZ, Tasirin SM. Comparative study of droplet drying models for CFD modelling. Chem Eng Res Des 2008;86:1038-48.

[146] Mezhericher M, Levy A, Borde I. Three-dimensional spray-drying model based on comprehensive formulation of drying kinetics. Dry Technol 2012;30:1256-73. 
[147] Woo MW, Wan Daud WR, Tasirin SM, Talib MZM. Effect of wall surface properties at different drying kinetics on the deposition problem in spray drying. Dry Technol 2008;26:15-26.

[148] Mezhericher M, Levy A, Borde I. Spray drying modelling based on advanced droplet drying kinetics. Chem Eng Process Process Intensif 2010;49:1205-13.

[149] Mezhericher M, Levy A, Borde I. Modelling the morphological evolution of nanosuspension droplet in constant-rate drying stage. Chem Eng Sci 2011;66:884-96.

[150] Aversa M, Curcio S, Calabrò V, Iorio G. An analysis of the transport phenomena occurring during food drying process. J Food Eng 2007;78:922-32.

[151] Chen P, Pei DCT. A mathematical model of drying processes 1989;32:297-310.

[152] Lemus-Mondaca RA, Zambra CE, Vega-Gálvez A, Moraga NO. Coupled 3D heat and mass transfer model for numerical analysis of drying process in papaya slices. J Food Eng 2013;116:109-17.

[153] Lemus-Mondaca RA, Vega-Gálvez A, Moraga NO. Computational simulation and developments applied to food thermal processing. Food Eng Rev 2011;3:121-35.

[154] Erriguible A, Bernada P, Couture F, Roques MA. Simulation of convective drying of a porous medium with boundary conditions provided by CFD. Chem Eng Res Des 2006;84:113-23.

[155] Dhall A, Squier G, Geremew M, Wood WA, George J, Datta AK. Modeling of multiphase transport during drying of honeycomb ceramic substrates. Dry Technol 2012;30:607-18.

[156] Belhamri A, Fohr J-P. Heat and mass transfer along a wetted porous plate in an air stream. AIChE J 1996;42:1833-43.

[157] Belessiotis V, Delyannis E. Solar drying. Sol Energy 2011;85:1665-91.

[158] Islam RM, Mujumdar AS. Role of product shrinkage in drying rate predictions using a liquid diffusion model. Int Commun Heat Mass Transf 2003;30:391-400.

[159] Queiroz MR, Nebra SA. Theoretical and experimental analysis of the drying kinetics of bananas. J Food Eng 2001;47:127-32.

[160] Mayor L, Sereno AM. Modelling shrinkage during convective drying of food materials: a review. J Food Eng 2004;61:373-86.

[161] Rahman MS. Toward prediction of porosity in foods during drying: a brief review. Dry Technol 2001;19:1-13.

[162] Whitaker S. Flow in porous media III: Deformable media. Transp Porous Media 1986;1:127-54. 
[163] Schrefler BA. Mechanics and thermodynamics of saturated/unsaturated porous materials and quantitative solutions. Appl Mech Rev 2002;55:351-88.

[164] Aregawi W, Defraeye T, Verboven P, Herremans E, Roeck G, Nicolai B. Modeling of coupled water transport and large deformation during dehydration of apple tissue. Food Bioprocess Technol 2013;6:1963-78.

[165] Singh PP, Cushman JH, Maier DE. Multiscale fluid transport theory for swelling biopolymers. Chem Eng Sci 2003;58:2409-19.

[166] Singh PP, Maier DE, Cushman JH, Campanella OH. Effect of viscoelastic relaxation on moisture transport in foods . Part II : Sorption and drying of soybeans. J Math Biol 2004;49:20-34.

[167] Singh PP, Maier DE, Cushman JH. Effect of viscoelastic relaxation on moisture transport in foods . Part I : Solution of general transport equation. J Math Biol 2004;49:1-19.

[168] Takhar PS, Maier DE, Campanella OH, Chen G. Hybrid mixture theory based moisture transport and stress development in corn kernels during drying: Validation and simulation results. J Food Eng 2011;106:275-82.

[169] Takhar PS. Hybrid mixture theory based moisture transport and stress development in corn kernels during drying: Coupled fluid transport and stress equations. J Food Eng 201 1;105:663-70.

[170] Zhu H, Dhall A, Mukherjee S, Datta AK. A model for flow and deformation in unsaturated swelling porous media. Transp Porous Media 2010;84:335-69.

[171] Misra S, Ramesh KT, Okamura AM. Modeling of tool-tissue interactions for computer-based surgical simulation: A literature review. Presence Teleoperators Virtual Environ 2008;17:463-91.

[172] Perré P, May BK. A numerical drying model that accounts for the coupling between transfers and solid mechanics. Case of highly deformable products. Dry Technol 2001;19:1629-43.

[173] Perré P, Passard J. A physical and mechanical model able to predict the stress field in wood over a wide range of drying conditions. Dry Technol 2004;22:27-44.

[174] Akiyama T, Hayakawa K-I. Heat and moisture transfer and hygrophysical changes in elastoplastic hollow cylinder-food during drying. Food Eng Phys Prop 2000;65:315-23.

[175] Moonen P, Sluys LJ, Carmeliet J. A continuous - discontinuous approach to simulate physical degradation processes in porous media. Int J Numer Methods Eng 2010;84:1009-37.

[176] Rakesh V, Datta AK, Walton JH, McCarthy KL, McCarthy MJ. Microwave combination heating: Coupled electromagnetics- multiphase porous media modeling and MRI experimentation. AIChE J 2012;58:1262-78. 
[177] Datta AK, Rakesh V. Principles of microwave combination heating. Compr Rev Food Sci Food Saf 2013;12:24-39.

[178] Marra F, De Bonis MV, Ruocco G. Combined microwaves and convection heating: A conjugate approach. J Food Eng 2010;97:31-9.

[179] Ranjbaran M, Zare D. CFD modeling of microwave-assisted fluidized bed drying of moist particles using two-fluid model. Dry Technol 2012;30:362-76.

[180] Prachayawarakorn S, Choteboon C, Soponronnarit S. Simultaneous momentum, heat, and mass transfer with color change during paddy storage in silo. Dry Technol 2005;23:205-23.

[181] Van Boekel MAJS. Kinetic modeling of food quality: A critical review. Compr Rev Food Sci Food Saf 2008;7:144-58.

[182] Banga JR, Balsa-Canto E, Moles CG, Alonso AA. Improving food processing using modern optimization methods. Trends Food Sci Technol 2003;14:131-44.

[183] Halder A, Datta AK, Spanswick RM. Water transport in cellular tissues during thermal processing. AIChE J 2011;57:2574-88.

[184] Ho QT, Carmeliet J, Datta AK, Defraeye T, Delele MA, Herremans E, et al. Multiscale modeling in food engineering. J Food Eng 2013;114:279-91.

[185] Kohout M, Stepanek F. Multi-scale analysis of vacuum contact drying. Dry Technol 2007;25:1265-73.

[186] Novak V, Koci P, Stepanek F, Marek M. Integrated multiscale methodology for virtual prototyping of porous catalysts. Ind Eng Chem Res 2011;50:12904-14.

[187] Perré P. Multiscale aspects of heat and mass transfer during drying. Transp Porous Media 2007;66:59-76.

[188] Bruchmüller J, Wachem B van, Gu S. Modeling the thermochemical degradation of biomass inside a fast pyrolysis fluidized bed reactor. AIChE J 2012;58:3030-42.

[189] Zhang K, You C. Experimental and numerical investigation of lignite particle drying in a fixed bed. Energy \& Fuels 2011;25:4014-23.

[190] Perré P, Rémond R, Colin J, Mougel E, Almeida G. Energy consumption in the convective drying of timber analyzed by a multiscale computational model. Dry Technol 2012;30:1136-46.

[191] Perré P, Rémond R, Aléon D. Energy saving in industrial wood drying addressed by a multiscale computational model: board, stack, and kiln. Dry Technol 2007;25:75-84. 
[192] Perré P, Rémond R. A dual-scale computational model of kiln wood drying including single board and stack level simulation. Dry Technol 2006;24:1069-74.

[193] Li X, Rankin SE. Multiscale dynamic Monte Carlo/ continuum model of drying and nonideal polycondensation in sol-gel silica films. AIChE J 2010;56:2946-56.

[194] Li X, Rankin SE. Influence of unlimited 3-membered ring cyclization on a multiscale dynamic Monte Carlo/continuum model of drying and curing in sol-gel silica films. Chem Eng Sci 2011;66:1015-26.

[195] Wu Z, Xiao J, Huang Y, Qian Y. Integrated multiscale product and process control of polymeric coating curing. Chem Eng J 2010;161:269-75.

[196] Maekawa K, Ishida T, Kishi T. Multi-scale modeling of concrete performance integrated material and structural mechanics. J Adv Concr Technol 2003;1:91-126.

[197] Ishida T, Luan Y, Sagawa T, Nawa T. Modeling of early age behavior of blast furnace slag concrete based on micro-physical properties. Cem Concr Res 2011;41:1357-67.

[198] Maekawa K, Chijiwa N, Ishida T. Long-term deformational simulation of PC bridges based on the thermo-hygro model of micro-pores in cementitious composites. Cem Concr Res 2011;41:1310-9.

[199] E W. Principles of Multiscale Modeling. First edit. Cambridge: Cambridge University Press; 2011.

[200] Nassehi V, Parvazinia M. Finite element modeling of multiscale phenomena. First edit. London: Imperial College Press; 2010.

[201] Langrish TAG, Kockel TK. The assessment of a characteristic drying curve for milk powder for use in computational fluid dynamics modelling. Chem Eng J 2001;84:69-74.

[202] Van der Sman RGM, Meinders MBJ. Moisture diffusivity in food materials. Food Chem 2013;138:1265-74.

[203] Jin X, Sman RGM Van Der, van Boxtel AJB. Evaluation of the free volume theory to predict moisture transport and quality changes during broccoli drying. Dry Technol 2011;29:1963-71.

[204] Carmeliet J, Roels S. Determination of the moisture capacity of porous building materials. J Build Phys 2002;25:209-37.

[205] Carmeliet J, Hens H, Roels S, Adan O, Brocken H, Cerny R, et al. Determination of the liquid water diffusivity from transient moisture transfer experiments. J Build Phys 2004;27:277-305.

[206] Tremblay C, Cloutier A, Fortin Y. Determination of the effective water conductivity of red pine sapwood. Wood Sci Technol 2000;34:109-24. 
[207] Defraeye T, Blocken B, Carmeliet J. Influence of uncertainty in heat-moisture transport properties on convective drying of porous materials by numerical modelling. Chem Eng Res Des 2013;91:3642.

[208] Roels S, Carmeliet J, Hens H, Adan O, Brocken H, Cerny R, et al. Interlaboratory comparison of hygric properties of porous building materials. J Build Phys 2004;27:307-25.

[209] Roels S, Talukdar P, James C, Simonson CJ. Reliability of material data measurements for hygroscopic buffering. Int J Heat Mass Transf 2010;53:5355-63.

[210] Domínguez-Muñoz F, Anderson B, Cejudo-López JM, Carrillo-Andrés A. Uncertainty in the thermal conductivity of insulation materials. Energy Build 2010;42:2159-68.

[211] Nicolai B, De Baerdemaeker J. Finite element perturbation analysis of non-linear heat conduction problems with random field parameters. Int J Numer Methods Heat Fluid Flow 1997;7:525-44.

[212] Nicolai B, Scheerlinck N, Verboven P, De Baerdemaeker J. Stochastic perturbation analysis of thermal food processes with random field parameters. Trans ASAE 2000;43:131-8.

[213] Scheerlinck N, Verboven P, Stigter J, De Baerdemaeker J, Van Impe J, Nicolai B. Stochastic finite element analysis of coupled heat and mass transfer problems with random field parameters. Numer Heat Transf Part B - Fundam 2000;37:309-30.

[214] Cronin K, Kearney S. Monte Carlo modelling of a vegetable tray dryer 1998;35:233-50.

[215] Tanaka F, Maeda Y, Uchino T, Hamanaka D, Atungulu GG. Monte Carlo simulation of the collective behavior of food particles in pneumatic drying operation. LWT - Food Sci Technol 2008;41:1567-74.

[216] Lacasse D, Turgeon É, Pelletier D. On the judicious use of the k-E model, wall functions and adaptivity. Int J Therm Sci 2004;43:925-38.

[217] Tsotsas E, Mujumdar AS. Modern Drying Technology - Volume 2 - Experimental Techniques. Weinheim: Wiley-VCH Verlag GmbH; 2009.

[218] Koptyug I V. MRI of mass transport in porous media: drying and sorption processes. Prog Nucl Magn Reson Spectrosc 2012;65:1-65.

[219] Hillenbach A, Engelhardt M, Abele H, Gähler R. High flux neutron imaging for high-speed radiography, dynamic tomography and strongly absorbing materials. Nucl Instruments Methods Phys Res Sect A Accel Spectrometers, Detect Assoc Equip 2005;542:116-22.

[220] Wu C, Cheng Y, Ding Y, Wei F, Jin Y. A novel X-ray computed tomography method for fast measurement of multiphase flow. Chem Eng Sci 2007;62:4325-35. 
[221] Hampel U, Speck M, Koch D, Menz H-J, Mayer H-G, Fietz J, et al. Experimental ultra fast X-ray computed tomography with a linearly scanned electron beam source. Flow Meas Instrum $2005 ; 16: 65-72$.

[222] Feinberg DA, Setsompop K. Ultra-fast MRI of the human brain with simultaneous multi-slice imaging. J Magn Reson 2013;229:90-100.

[223] Peglow M, Metzger T, Lee G, Schiffter H, Hampel R. Measurement of average moisture content and drying kinetics for single particles, droplets and dryers. In: Tsotsas E, Mujumdar AS, editors. Mod. Dry. Technol. - Vol. 2 - Exp. Tech., vol. 2, Wiley-VCH Verlag GmbH; 2009, p. 1-71.

[224] Le Page JF, Mirade P-S, Daudin J-D. Development of a device and method for the time-course estimation of low water fluxes and mean surface water activity of food products during ripening and storage. Food Res Int 2010;43:1180-6.

[225] Vitrac O, Trystram G. A method for time and spatially resolved measurement of convective heat transfer coefficient (h) in complex flows. Chem Eng Sci 2005;60:1219-36.

[226] Léonard A, Crine M, Stepanek F. Use of X-ray tomography for drying-related applications. In: Tsotsas E, Mujumdar AS, editors. vol. 2, Weinheim: Wiley-VCH Verlag GmbH; 2009, p. 143-86.

[227] Defraeye T, Aregawi W, Saneinejad S, Vontobel P, Lehmann E, Carmeliet J, et al. Novel application of neutron radiography to forced convective drying of fruit tissue. Food Bioprocess Technol 2012;6:3353-67.

[228] Patera A, Derome D, Griffa M, Carmeliet J. Hysteresis in swelling and in sorption of wood tissue. J Struct Biol 2013;182:226-34.

[229] Léonard A, Blacher S, Marchot P, Pirard J-P, Crine M. Image analysis of X-ray microtomograms of soft materials during convective drying: 3D measurements. J Microsc 2003;212:197-204.

[230] Moreno-Atanasio R, Williams RA, Jia X. Combining X-ray microtomography with computer simulation for analysis of granular and porous materials. Particuology 2010;8:81-99.

[231] Derome D, Griffa M, Koebel M, Carmeliet J. Hysteretic swelling of wood at cellular scale probed by phase-contrast X-ray tomography. J Struct Biol 2011;173:180-90.

[232] Derome D, Rafsanjani A, Patera A, Guyer R, Carmeliet J. Hygromorphic behaviour of cellular material : hysteretic swelling and shrinkage of wood probed by phase contrast X-ray tomography. Philos Mag 2012;92:3680-98.

[233] Mannes D, Marone F, Lehmann E, Stampanoni M, Niemz P. Application areas of synchrotron radiation tomographic microscopy for wood research. Wood Sci Technol 2009;44:67-84. 
[234] Verboven P, Kerckhofs G, Mebatsion HK, Ho QT, Temst K, Wevers M, et al. Three-dimensional gas exchange pathways in pome fruit characterized by synchrotron X-ray. Plant Physiol 2008;147:518-27.

[235] Verboven P, Pedersen O, Herremans E, Ho QT, Nicolai B, Colmer TD, et al. Root aeration via aerenchymatous phellem: three-dimensional micro-imaging and radial $\mathrm{O} 2$ profiles in Melilotus siculus. New Phytol 2012;193:420-31.

[236] Derluyn H, Griffa M, Mannes D, Jerjen I, Dewanckele J, Vontobel P, et al. Characterizing saline uptake and salt distributions in porous limestone with neutron radiography and X-ray microtomography. J Build Phys 2013;36:353-74.

[237] Kohout M, Grof Z, Stepanek F. Pore-scale modelling and tomographic visualisation of drying in granular media. J Colloid Interface Sci 2006;299:342-51.

[238] Aregawi W, Defraeye T, Saneinejad S, Vontobel P, Lehmann E, Carmeliet J, et al. Dehydration of apple tissue: Intercomparison of neutron tomography with numerical modelling. Int J Heat Mass Transf 2013;67:173-82.

[239] Aghbashlo M, Mobli H, Rafiee S, Madadlou A. A review on exergy analysis of drying processes and systems. Renew Sustain Energy Rev 2013;22:1-22.

[240] Hepbasli A. A key review on exergetic analysis and assessment of renewable energy resources for a sustainable future. Renew Sustain Energy Rev 2008;12:593-661.

[241] Oztop HF, Bayrak F, Hepbasli A. Energetic and exergetic aspects of solar air heating (solar collector) systems. Renew Sustain Energy Rev 2013;21:59-83.

[242] Gungor A, Erbay Z, Hepbasli A. Exergetic analysis and evaluation of a new application of gas engine heat pumps (GEHPs) for food drying processes. Appl Energy 2011;88:882-91.

[243] Gungor A, Erbay Z, Hepbasli A. Exergoeconomic analyses of a gas engine driven heat pump drier and food drying process. Appl Energy 2011;88:2677-84.

[244] Gustavsson J, Cederberg C, Sonesson U, van Otterdijk R, Meybeck A. Global food losses and food wastes - extent, causes and prevention (www.fao.org). Rome, Italy: 2011.

[245] Jairaj KS, Singh SP, Srikant K. A review of solar dryers developed for grape drying. Sol Energy 2009;83:1698-712.

[246] Bal LM, Satya S, Naik SN. Solar dryer with thermal energy storage systems for drying agricultural food products: A review. Renew Sustain Energy Rev 2010;14:2298-314.

[247] VijayaVenkataRaman S, Iniyan S, Goic R. A review of solar drying technologies. Renew Sustain Energy Rev 2012;16:2652-70. 
[248] Tsotsas E, Mujumdar AS. Modern Drying Technology - Vol 4 - Energy Savings, Volume 4. First edit. Weinheim: Wiley-VCH Verlag GmbH; 2011.

[249] Aziz M, Oda T, Kashiwagi T. Enhanced high energy efficient steam drying of algae. Appl Energy 2013;109:163-70.

[250] Hong S, Ryu C, Ko HS, Ohm T-I, Chae J-S. Process consideration of fry-drying combined with steam compression for efficient fuel production from sewage sludge. Appl Energy 2013;103:46876.

[251] Rathore NS, Panwar NL. Experimental studies on hemi cylindrical walk-in type solar tunnel dryer for grape drying. Appl Energy 2010;87:2764-7.

[252] Hoff H. Understanding the Nexus. Background paper for the Bonn2011 Nexus Conference: The Water, Energy and Food Security Nexus. Stockholm Environment Institute; 2011.

[253] Bazilian M, Rogner H, Howells M, Hermann S, Arent D, Gielen D, et al. Considering the energy, water and food nexus: Towards an integrated modelling approach. Energy Policy 2011;39:7896906.

[254] Fortin Y, Defo M, Nabhani M, Tremblay C, Gendron G. A simulation tool for the optimization of lumber drying schedules. Dry Technol 2004;22:963-83.

[255] Anderson J-O, Westerlund L. Improved energy efficiency in sawmill drying system. Appl Energy 2014;113:891-901.

[256] FAO. Energy-Smart Food at FAO: An overview (www.fao.org). Rome, Italy: 2012.

[257] Masmoudi W, Prat M. Heat and mass transfer between a porous medium and a parallel external flow. Application to drying of capillary porous materials. Int J Heat Mass Transf 1991;34:1975-89.

[258] Zeghmati B, Daguenet M, Le Palec G. Study of transient laminar free convection over an inclined wet flat plate. Int J Heat Mass Transf 1991;34:899-909.

[259] Dolinskiy AA, Dorfman ASH, Davydenko BV. Conjugate heat and mass transfer in continuous processes of convective drying. Int J Heat Mass Transf 1991;34:2883-9.

[260] Oliveira LS, Fortes M, Haghighi K. Conjugate analysis of natural convective drying of biological materials. Dry Technol 1994;12:1167-90.

[261] Oliveira LS, Haghighi K. Conjugate heat and mass transfer in convective drying of porous media. Numer Heat Transf Part A Appl 1998;34:105-17.

[262] Suresh HN, Aswatha Narayana PA, Seetharamu KN. Conjugate mixed convection heat and mass transfer in brick drying. Heat Mass Transf 2001;37:205-13. 
[263] Murugesan K, Suresh HN, Seetharamu KN, Aswatha Narayana PA, Sundararajan T. A theoretical model of brick drying as a conjugate problem. Int J Heat Mass Transf 2001;44:4075-86.

[264] Erriguible A, Bernada P, Couture F, Roques MA. Modeling of heat and mass transfer at the boundary between a porous medium and its surroundings. Dry Technol 2005;23:455-72.

[265] Younsi R, Kocaefe D, Poncsak S, Kocaefe Y. Computational modelling of heat and mass transfer during the high-temperature heat treatment of wood. Appl Therm Eng 2007;27:1424-31.

[266] Curcio S, Aversa M, Calabrò V, Iorio G. Simulation of food drying: FEM analysis and experimental validation. J Food Eng 2008;87:541-53.

[267] Younsi R, Kocaefe D, Poncsak S, Kocaefe Y, Gastonguay L. CFD modeling and experimental validation of heat and mass transfer in wood poles subjected to high temperatures: a conjugate approach. Heat Mass Transf 2008;44:1497-509.

[268] De Bonis M V., Ruocco G. A generalized conjugate model for forced convection drying based on an evaporative kinetics. J Food Eng 2008;89:232-40.

[269] Lamnatou C, Papanicolaou E, Belessiotis V, Kyriakis N. Conjugate heat and mass transfer from a drying rectangular cylinder in confined air flow. Numer Heat Transf Part A Appl 2009;56:379405.

[270] Lamnatou C, Papanicolaou E, Belessiotis V, Kyriakis N. Finite-volume modelling of heat and mass transfer during convective drying of porous bodies - Non-conjugate and conjugate formulations involving the aerodynamic effects. Renew Energy 2010;35:1391-402.

[271] Kays WM, Crawford ME. Convective Heat and Mass Transfer. Third edit. USA: McGraw-Hill; 1993.

[272] Léonard A, Blacher S, Marchot P, Pirard J-P, Crine M. Measurement of shrinkage and cracks associated to convective drying of soft materials by X-ray microtomography. Dry Technol 2004;22:1695-708.

[273] Léonard A, Blacher S, Marchot P, Pirard J-P, Crine M. Moisture profiles determination during convective drying using X-ray microtomography. Can J Chem Eng 2005;83:127-31.

[274] Alkan S, Zhang Y, Lam F. Moisture distribution changes and wetwood behavior in subalpine fir wood during drying using high X-ray energy industrial CT scanner. Dry Technol 2007;25:483-8.

[275] Baettig R, Rémond R, Perré P. Measuring moisture content profiles in a board during drying: a polychromatic X-ray system interfaced with a vacuum/pressure laboratory kiln. Wood Sci Technol 2006;40:261-74.

[276] Watanabe K, Saito Y, Avramidis S, Shida S. Non-destructive measurement of moisture distribution in wood during drying using digital X-ray microscopy. Dry Technol 2008;26:590-5. 
[277] Potter a. R, Austin JC, Ormerod RM, Haycock PW, Heywood BR, George SD. X-ray images of defect formation in porcelain ceramics during drying. NDT E Int 2003;36:77-83.

[278] Shokri N, Sahimi M. Structure of drying fronts in three-dimensional porous media. Phys Rev E 2012;85:066312.

[279] Balasko M, Korosi F, Farkas I. Applying dynamic neutron radiography in in-situ monitoring of the drying processes of apple. Dev Chem Eng Miner Process 2002;10:247-60.

[280] Shokri N, Lehmann E, Vontobel P, Or D. Drying front and water content dynamics during evaporation from sand delineated by neutron radiography. Water Resour Res 2008;44:n/a-n/a.

[281] Nakanishi TM, Okano T, Karakama I, Ishihara T, Matsubayashi M. Three dimensional imaging of moisture in wood disk by neutron beam during drying process. Holzforschung 1998;52:673-6.

[282] Nguyen TA, Dresselaers T, Verboven P, D'hallewin G, Culeddu N, Van Hecke P, et al. Finite element modelling and MRI validation of 3D transient water profiles in pears during postharvest storage. J Sci Food Agric 2006;86:745-56.

[283] Mantle M., Reis N., Griffiths R., Gladden L. MRI studies of the evaporation of a single liquid droplet from porous surfaces. Magn Reson Imaging 2003;21:293-7.

[284] Koptyug I V, Kabanikhin S., Iskakov K., Fenelonov V., Khitrina LY, Sagdeev R., et al. A quantitative NMR imaging study of mass transport in porous solids during drying. Chem Eng Sci 2000;55:1559-71.

[285] Stenstrom S, Bonazzi C, Foucat L. Magnetic Resonance Imaging for Determination of Moisture Profiles and Drying Curves. In: Tsotsas E, Mujumdar AS, editors. Mod. Dry. Technol. - Vol 2 Exp. Tech., vol. 2, Weinheim: Wiley-VCH Verlag GmbH; 2009, p. 91-142.

[286] Frias JM, Foucat L, Bimbenet JJ, Bonazzi C. Modeling of moisture profiles in paddy rice during drying mapped with magnetic resonance imaging. Chem Eng J 2002;86:173-8.

[287] Zhao C-X, Shao H-B, Chu L-Y. Aquaporin structure-function relationships: water flow through plant living cells. Colloids Surf B Biointerfaces 2008;62:163-72.

[288] Fanta SW, Vanderlinden W, Abera MK, Verboven P, Karki R, Ho QT, et al. Water transport properties of artificial cell walls. J Food Eng 2012;108:393-402.

[289] Herremans E, Verboven P, Bongaers E, Estrade P, Verlinden BE, Wevers M, et al. Characterisation of "Braeburn" browning disorder by means of X-ray micro-CT. Postharvest Biol Technol 2013;75:114-24.

[290] Defraeye T, Lehmann V, Gross D, Holat C, Herremans E, Verboven P, et al. Application of MRI for tissue characterisation of "Braeburn" apple. Postharvest Biol Technol 2013;75:96-105. 
[291] Lee JM, Pawlak JJ, Heitmann JA. Longitudinal and concurrent dimensional changes of cellulose aggregate fibrils during sorption stages. Mater Charact 2010;61:507-17.

[292] Rosenthal M, Bäucker E. Zur Anatomie des Fichtenholzes. 2012.

[293] Derome D, Rafsanjani A, Hering S, Dressler M, Patera A, Lanvermann C, et al. The role of water in the behavior of wood. J Build Phys 2013;36:398-421.

[294] Rafsanjani A, Lanvermann C, Niemz P, Carmeliet J, Derome D. Multiscale analysis of free swelling of Norway spruce. Compos Part A Appl Sci Manuf 2013;54:70-8.

[295] Smit GJF, du Plessis JP. Modelling of airflow through a stack in a timber-drying kiln. Appl Math Model 2007;31:270-82.

[296] Hazra C, Bari S, Kundu D, Chaudhari A, Mishra S, Chatterjee A. Ultrasoundassisted/biosurfactant-templated size-tunable synthesis of nano-calcium sulfate with controllable crystal morphology. Ultrason Sonochem 2014;21:1117-31.

[297] Da Silva Almeida G, Barbosa da Silva J, Joaquina e Silva C, Swarnakar R, de Araújo Neves G, Barbosa de Lima AG. Heat and mass transport in an industrial tunnel dryer: Modeling and simulation applied to hollow bricks. Appl Therm Eng 2013;55:78-86. 


\section{APPENDIX 1: Search queries in Scopus for statistics in Figure 1 and Figure 4}

The statistics on the number of papers on drying technology in relation to energy, food and modelling (Figure 1), and advanced computational methods (Figure 4) were obtained from Scopus (http://www.scopus.com/, statistics were acquired on 08/10/2013). This implied searching for specific keywords, e.g. drying AND modelling, within the Scopus database. Search queries were restricted more in detail in order to avoid that the results were biased by papers which contained these keywords, but were not relevant to drying technology. To this end, only selected journals in specific fields of research were considered. Note that the relevance of the results from the search with respect to drying technology was verified.

Following keyword combinations were searched for:

- Figure 1
○ Drying
- Drying AND energy
- Drying AND food
○ Drying AND (modelling OR modeling)

- $\quad$ Figure 4
○ Drying
- Drying AND (modelling OR modeling)
- drying AND (multiscale OR multi-scale)
- drying AND (computational fluid dynamics OR CFD)
- drying AND (multiscale OR multi-scale)
- drying AND conjugate AND model

The search was restricted to following journals (ordered alphabetically):

- Aiche Journal

- Animal Feed Science and Technology

- Applied Energy

- Applied Engineering in Agriculture

- Applied Solar Energy English Translation of Geliotekhnika

- Applied Thermal Engineering

- Biomass and Bioenergy

- Biosystems Engineering

- Brazilian Journal of Chemical Engineering

- Cement and Concrete Composites

- Cement and Concrete Research

- Ceramics International

- Chemical Engineering and Processing Process Intensification

- Chemical Engineering and Technology

- Chemical Engineering Journal

- Chemical Engineering Science

- Construction and Building Materials

- Drying

- Drying Technology

- Energy 
- Energy and Fuels

- Energy Conversion and Management

- European Food Research and Technology

- Fibre Chemistry

- Field Crops Research

- Food and Bioprocess Technology

- Food and Bioproducts Processing

- Food Research International

- Food Science and Biotechnology

- Food Science and Technology International

- Forest Products Journal

- Huaxue Gongcheng Chemical Engineering China

- Industrial and Engineering Chemistry Research

- Industrial Crops and Products

- Innovative Food Science and Emerging Technologies

- International Communications in Heat and Mass Transfer

- International Dairy Journal

- International Journal of Energy Research

- International Journal of Food Engineering

- International Journal of Food Properties

- International Journal of Food Science and Technology

- International Journal of Heat and Mass Transfer

- Journal of Agricultural and Food Chemistry

- Journal of Agricultural Engineering Research

- Journal of Chemical Engineering of Japan

- Journal of Engineering Physics

- Journal of Engineering Physics and Thermophysics

- Journal of Experimental Botany

- Journal of Food Agriculture and Environment

- Journal of Food Engineering

- Journal of Food Process Engineering

- Journal of Food Processing and Preservation

- Journal of Food Protection

- Journal of Food Science

- Journal of Food Science and Technology

- Journal of Materials in Civil Engineering

- Journal of Porous Materials

- Journal of Stored Products Research

- Journal of the Science of Food and Agriculture

- Journal of Wood Science

- Magazine of Concrete Research

- Materials Letters

- Meat Science

- Microporous and Mesoporous Materials 
Defraeye T., Advanced computational modelling for drying processes - a review, Applied Energy 131, 323-344. http://dx.doi.org/10.1016/j.apenergy.2014.06.027

- Renewable Energy

- Scientia Horticulturae

- Soil and Tillage Research

- Solar Energy

- Textile Research Journal

- Theoretical Foundations of Chemical Engineering

- Transactions of the American Society of Agricultural Engineers

- Transport in Porous Media

- Wood and Fiber Science

- Wood Science and Technology

- ZI Ziegelindustrie International Brick and Tile Industry International

An example of an input query can be found below (for drying AND (modelling OR modeling))

(TITLE-ABS-KEY(drying AND (modelling OR modeling)) AND DOCTYPE(ar OR re) ) AND ( LIMIT-TO(SUBJAREA,"AGRI" ) OR LIMIT-TO(SUBJAREA, "CENG" ) OR LIMIT-TO(SUBJAREA, "ENGI" ) OR LIMIT-TO(SUBJAREA,"ENER" ) ) AND ( LIMIT-TO(SRCTYPE,"j" ) ) AND ( LIMIT-TO(EXACTSRCTITLE,"Drying Technology" ) OR LIMIT-TO(EXACTSRCTITLE,"Journal of Food Engineering" ) OR LIMIT-TO(EXACTSRCTITLE,"Journal of Agricultural and Food Chemistry" ) OR LIMITTO(EXACTSRCTITLE,"Cement and Concrete Research" ) OR LIMIT-TO(EXACTSRCTITLE,"Forest Products Journal" ) OR LIMIT-TO(EXACTSRCTITLE, "Transactions of the American Society of Agricultural Engineers" ) OR LIMIT-TO(EXACTSRCTITLE,"Journal of Food Science and Technology" ) OR LIMIT-

TO(EXACTSRCTITLE,"International Journal of Food Science and Technology" ) OR LIMIT-TO(EXACTSRCTITLE,"Chemical Engineering Science" ) OR LIMITTO(EXACTSRCTITLE,"Industrial and Engineering Chemistry Research" ) OR LIMIT-TO(EXACTSRCTITLE,"Journal of Food Science" ) OR LIMIT-

TO(EXACTSRCTITLE,"International Journal of Heat and Mass Transfer" ) OR LIMIT-TO(EXACTSRCTITLE,"Journal of the Science of Food and Agriculture" ) OR LIMIT-TO(EXACTSRCTITLE,"Journal of Agricultural Engineering Research" ) OR LIMIT-TO(EXACTSRCTITLE,"Construction and Building Materials" ) OR LIMITTO(EXACTSRCTITLE, "Wood Science and Technology" ) OR LIMIT-TO(EXACTSRCTITLE,"Food Research International" ) OR LIMIT-TO(EXACTSRCTITLE,"Journal of Experimental Botany" ) OR LIMIT-TO(EXACTSRCTITLE,"Meat Science" ) OR LIMIT-TO(EXACTSRCTITLE,"Journal of Engineering Physics" ) OR LIMITTO(EXACTSRCTITLE,"Energy Conversion and Management" ) OR LIMIT-TO(EXACTSRCTITLE,"European Food Research and Technology" ) OR LIMITTO(EXACTSRCTITLE, "Biosystems Engineering" ) OR LIMIT-TO(EXACTSRCTITLE,"Food and Bioproducts Processing" ) OR LIMIT-TO(EXACTSRCTITLE,"Renewable Energy" ) OR LIMIT-TO(EXACTSRCTITLE,"Journal of Food Process Engineering" ) OR LIMIT-TO(EXACTSRCTITLE,"Applied Engineering in Agriculture" ) OR LIMITTO(EXACTSRCTITLE,"International Journal of Food Engineering" ) OR LIMIT-TO(EXACTSRCTITLE,"Chemical Engineering and Processing Process Intensification" ) OR LIMIT-TO(EXACTSRCTITLE,"Journal of Food Processing and Preservation" ) OR LIMIT-TO(EXACTSRCTITLE,"Microporous and Mesoporous Materials" ) OR LIMIT-TO(EXACTSRCTITLE,"Aiche Journal" ) OR LIMIT-TO(EXACTSRCTITLE,"Industrial Crops and Products" ) OR LIMIT-TO(EXACTSRCTITLE,"Animal Feed Science and Technology" ) OR LIMIT-TO(EXACTSRCTITLE,"Cement and Concrete Composites" ) OR LIMIT-TO(EXACTSRCTITLE,"Fibre Chemistry" ) OR LIMITTO(EXACTSRCTITLE,"Biomass and Bioenergy" ) OR LIMIT-TO(EXACTSRCTITLE,"Journal of Food Protection" ) OR LIMIT-TO(EXACTSRCTITLE,"ZI Ziegelindustrie International Brick and Tile Industry International" ) OR LIMIT-TO(EXACTSRCTITLE,"Applied Solar Energy English Translation of Geliotekhnika" ) OR LIMITTO(EXACTSRCTITLE,"International Journal of Food Properties" ) OR LIMIT-TO(EXACTSRCTITLE,"Soil and Tillage Research" ) OR LIMIT-

TO(EXACTSRCTITLE, "Wood and Fiber Science" ) OR LIMIT-TO(EXACTSRCTITLE,"Applied Thermal Engineering" ) OR LIMIT-TO(EXACTSRCTITLE,"Food and Bioprocess Technology" ) OR LIMIT-TO(EXACTSRCTITLE,"Chemical Engineering and Technology" ) OR LIMIT-TO(EXACTSRCTITLE,"Chemical Engineering Journal" ) OR LIMIT-TO(EXACTSRCTITLE,"Journal of Chemical Engineering of Japan" ) OR LIMIT-TO(EXACTSRCTITLE,"International Journal of Energy Research" ) OR LIMIT-TO(EXACTSRCTITLE,"Ceramics International" ) OR LIMIT-TO(EXACTSRCTITLE,"Scientia Horticulturae" ) OR LIMIT-TO(EXACTSRCTITLE,"Journal of Materials in Civil Engineering" ) OR LIMIT-TO(EXACTSRCTITLE,"Energy and Fuels" ) OR LIMIT-TO(EXACTSRCTITLE,"Solar Energy" ) OR LIMIT-

TO(EXACTSRCTITLE,"Energy" ) OR LIMIT-TO(EXACTSRCTITLE,"Brazilian Journal of Chemical Engineering" ) OR LIMIT-TO(EXACTSRCTITLE,"Transport in Porous Media" ) OR LIMIT-TO(EXACTSRCTITLE,"Field Crops Research" ) OR LIMIT-TO(EXACTSRCTITLE,"Textile Research Journal" ) OR LIMIT-

TO(EXACTSRCTITLE,"Innovative Food Science and Emerging Technologies" ) OR LIMIT-TO(EXACTSRCTITLE,"Magazine of Concrete Research" ) OR LIMITTO(EXACTSRCTITLE,"Materials Letters" ) OR LIMIT-TO(EXACTSRCTITLE,"Journal of Food Agriculture and Environment" ) OR LIMITTO(EXACTSRCTITLE,"International Communications in Heat and Mass Transfer" ) OR LIMIT-TO(EXACTSRCTITLE,"International Dairy Journal" ) OR LIMITTO(EXACTSRCTITLE, "Journal of Engineering Physics and Thermophysics" ) OR LIMIT-TO(EXACTSRCTITLE,"Theoretical Foundations of Chemical Engineering" ) OR LIMIT-TO(EXACTSRCTITLE,"Journal of Porous Materials" ) OR LIMIT-TO(EXACTSRCTITLE,"Journal of Stored Products Research" ) OR LIMITTO(EXACTSRCTITLE,"Huaxue Gongcheng Chemical Engineering China" ) OR LIMIT-TO(EXACTSRCTITLE,"Food Science and Biotechnology" ) OR LIMITTO(EXACTSRCTITLE,"Food Science and Technology International" ) OR LIMIT-TO(EXACTSRCTITLE, "Applied Energy" ) OR LIMIT-TO(EXACTSRCTITLE,"Journal of Wood Science" ) OR LIMIT-TO(EXACTSRCTITLE,"Drying" ) ) 
Defraeye T., Advanced computational modelling for drying processes - a review, Applied Energy 131, 323-344. http://dx.doi.org/10.1016/j.apenergy.2014.06.027 